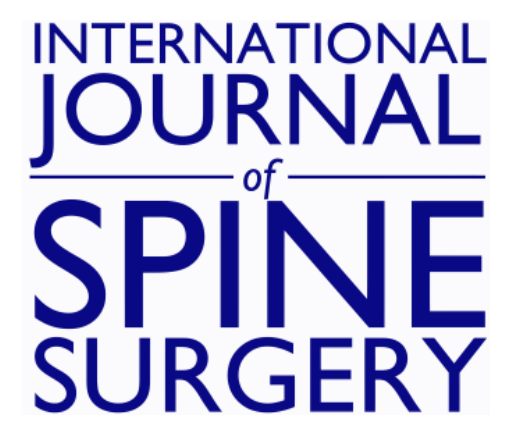

\title{
Bone substitutes and expanders in Spine Surgery: A review of their fusion efficacies
}

Abhijeet Kadam, Paul W Millhouse, Christopher K Kepler, Kris E. Radcliff, Michael G. Fehlings, Michael E. Janssen, Rick C. Sasso, James J. Benedict and Alexander R Vaccaro

Int J Spine Surg 2016, 10 ()

doi: https://doi.org/10.14444/3033

http://ijssurgery.com/content/10/33

This information is current as of April 26, 2023.

Email Alerts Receive free email-alerts when new articles cite this article. Sign up at:

http://ijssurgery.com/alerts

The International Journal of Shing Surgerih 2397 Waterbury Circle, Suite 1,

Aurora, IL 60504, Phone: +1-630-375-1432 


\section{Bone substitutes and expanders in Spine Surgery: A review of their fusion efficacies}

Abhijeet Kadam, MD, ${ }^{1}$ Paul $W$ Millhouse, $M D,{ }^{2}$ Christopher K Kepler, $M D, M B A,{ }^{2}$ Kris E. Radcliff, MD, ${ }^{2}$ Michael G. Fehlings MD, PhD, FRCSC, ${ }^{3}$ Michael E. Janssen, DO, ${ }^{4}$ Rick C. Sasso, MD, James J. Benedict, PhD, MD, ${ }^{6}$ Alexander $R$ Vaccaro, $M D, P h D, M B A^{2}$

${ }^{1}$ Pennsylvania Hospital of the University of Pennsylvania Health System, Philadelphia, PA ${ }^{2}$ Rothman Institute, Philadelphia, PA, ${ }^{3}$ Toronto Western Hospital, Toronto, Canada, ${ }^{4}$ Center for Spine \& Orthopaedics, Denver, CO, ${ }^{5}$ Indiana Spine Group, Indianapolis, IN, ${ }^{6}$ Cerapedics, Westminster, CO

\section{Abstract}

Study Design

A narrative review of literature.

Objective

This manuscript intends to provide a review of clinically relevant bone substitutes and bone expanders for spinal surgery in terms of efficacy and associated clinical outcomes, as reported in contemporary spine literature.

\section{Summary of Background Data}

Ever since the introduction of allograft as a substitute for autologous bone in spinal surgery, a sea of literature has surfaced, evaluating both established and newly emerging fusion alternatives. An understanding of the available fusion options and an organized evidence-based approach to their use in spine surgery is essential for achieving optimal results.

\section{Methods}

A Medline search of English language literature published through March 2016 discussing bone graft substitutes and fusion extenders was performed. All clinical studies reporting radiological and/or patient outcomes following the use of bone substitutes were reviewed under the broad categories of Allografts, Demineralized Bone Matrices (DBM), Ceramics, Bone Morphogenic proteins (BMPs), Autologous growth factors (AGFs), Stem cell products and Synthetic Peptides. These were further grouped depending on their application in lumbar and cervical spine surgeries, deformity correction or other miscellaneous procedures viz. trauma, infection or tumors; wherever data was forthcoming. Studies in animal populations and experimental in vitro studies were excluded. Primary endpoints were radiological fusion rates and successful clinical outcomes.

Results

A total of 181 clinical studies were found suitable to be included in the review. More than a third of the published articles (62 studies, 34.25\%) focused on BMP. Ceramics (40 studies) and Allografts (39 studies) were the other two highly published groups of bone substitutes. Highest radiographic fusion rates were observed with BMPs, followed by allograft and DBM. There were no significant differences in the reported clinical outcomes across all classes of bone substitutes.

\section{Conclusions}

There is a clear publication bias in the literature, mostly favoring BMP. Based on the available data, BMP is however associated with the highest radiographic fusion rate. Allograft is also very well corroborated in the literature. The use of DBM as a bone expander to augment autograft is supported, especially in the lumbar spine. Ceramics are also utilized as bone graft extenders and results are generally supportive, although limited. The use of autologous growth factors is not substantiated at this time. Cell matrix or stem cell-based products and the synthetic peptides have inadequate data. More comparative studies are needed to evaluate the efficacy of bone graft substitutes overall.

KEYWORDS: BONE SUBSTITUTES, ALLOGRAFTS, DEMINERALIZED BONE MATRIX (DBM), SPINE FUSION, CERAMICS, $\beta$ TRICALCIUM PHOSPHATE ( $\beta$-TCP), HYDROXYAPATITE, RHBMP-2, OSTEOGENIC PROTEIN-1 (OP-1), AUTOLOGOUS GROWTH FACTORS, I-FACTOR, SYNTHETIC PEPTIDES 


\section{Introduction}

Bone grafts and bone substitutes are indispensable for achieving and maintaining fusion and intersegmental stability in spine surgery. Autologous bone has long been regarded as the gold standard for obtaining reliable spinal fusion, mainly because of its distinctive micro-architecture and biological properties, which provide the perfect blend of osteoconductive, osteoinductive and osteogenic elements. However, the supply of autologous bone graft is limited. Additionally, issues of sub-optimal bone quality in osteoporotic patients and donor site morbidity after graft harvest have compelled the orthopaedic community to look for other options. This need has spawned an industry, marked by the development of numerous bone graft alternatives. The discerning spine surgeon today has a wide array of options, from which to choose. An understanding of the particularities and the published clinical and radiological outcomes in the context of the contemporary spine literature is essential for optimal utilization of bone grafts in spinal surgery.

\section{Materials and Methods}

A review of clinical articles on the topic of bone graft substitutes/expanders/extenders was conducted. A PubMed search of English-language articles published through March 2016 was performed. The combination of search terms employed were: bone graft substitutes, bone graft alternatives, fusion extenders/expanders, spinal fusion, lumbar spine, cervical spine, spinal deformity, allografts, demineralized bone matrix, DBM, ceramics, calcium sulphate, $\beta$-tricalcium phosphate, hydroxyapatite, autologous growth factors, AGF, stem cells, rhBMP-2, rhBMP-7, and OP-1, synthetic peptides. The following commercial names of bone substitute products were also used to expand the results of the search: Grafton DBM, Accell Connexus, Healos, Polybone, Osferion, BioLu, Triosite, Bongros, Osteofil, Vitoss, Apaceram, Intepore, ChronOS, ProOsteon, Osteoset, Osteocel Plus, ActiFuse, Infuse, Amplify, i-Factor, Amplex. Two authors (AK \& PM) conducted the search independently and the results were compared. Only studies reporting radiological fusion rates (assessed using X-rays, CT scans and/or isotope bone scans) and/or clinical patient outcomes following the application of bone substitutes in spine surgery were included. Both prospective and retrospective studies were included. Case reports and small case series $(\mathrm{n}<10)$ were not reviewed. Studies on animal models were excluded, as were in-vitro studies without reported clinical measures.

All resulting articles were broadly grouped into the following categories: Allografts, Demineralized bone matrix (DBM), Ceramics, Osteogenic growth factors (namely Bone Morphogenic Proteins), Autologous growth factors (AGFs) (Platelet derived growth factors), Stem cell products (Allograft cellular bone matrix) and Synthetic peptides. Additionally, these were sub-categorized according to use in a particular anatomical segment of the spine, where applicable, or for a particular condition, such as spinal deformity. Articles were assigned levels of evidence according to the criteria described by Wright et al. ${ }^{1}$ Studies in each category and sub-class are discussed in a manner that places emphasis on higher level of evidence articles first, and in reverse chronological order from recent to remote.

\section{Results}

A total of 181 articles met the inclusion criteria (Allograft: 39, DBM: 20, Ceramics: 40, rhBMP-2: 54, rhBMP-7/OP-1: 8, Autologous growth factors: 9, Stem cells based products: 7, Synthetic Peptides 4). More than a third of the studies (62 studies, 34.25\%) were related to the use of Bone Morphogenic Proteins (BMP), making this the single largest group of published bone graft substitutes. Studies on ceramics (40) and allografts (39) were the next most extensively published. Autologous growth factors, Stem cell based substitutes and Synthetic peptides are relatively novel, and data thereof was less forthcoming.

\section{Allografts}

Allograft is bone derived from cadavers. They are highly osteoconductive, variably osteoinductive and lack osteogenic properties due to the loss of cellular elements during processing to reduce immunogenici- 
ty. Common processing techniques include freezing and lyophilization (i.e. freeze drying). Lyophilized allografts are processed by dehydration and vacuum packed, facilitating storage at room temperatures. ${ }^{2}$ The process of lyophilization reduces immunogenicity more than freezing but results in a greater reduction of mechanical strength on rehydration. ${ }^{3}$

\section{Allografts in cervical spine fusion}

Fourteen studies ${ }^{4-17}$ evaluating the use of allografts in surgery for degenerative cervical spine were identified (one level I ${ }^{4}$,two level II ${ }^{8,13}$, seven level III 6,7,9,10,15-17 and four level IV $\left.{ }^{5,11,12,14}\right)$. Graham et al. ${ }^{4}$ in a prospective randomized control trial (level I) comparing glycerol preserved versus freeze dried allografts for anterior cervical fusion reported fusion rates greater than $95 \%$ in both groups, which were not statistically different $(\mathrm{p}=0.2127$ and 0.1705 for the 3- and 6-month follow-up, respectively). However, no comparison with autograft was done by the authors in the study. In another prospective semirandomized comparative study, Suchomel et al. ${ }^{8}$ (level II) evaluated freeze-dried fibular allografts versus autologous iliac crest grafts in 80 patients undergoing instrumented anterior cervical fusions. Assessment of fusion was done with AP and lateral radiographs at various time points. In single-level procedures, there was no significant difference in fusion rates $(100 \%$ vs. $93.3 \%, \mathrm{p}=0.197)$ and graft collapse rates ( $0 \%$ vs. $3.4 \%, \mathrm{p}=0.365)$ between autograft and allograft, respectively. In two-level procedures the differences were also insignificant: $90.9 \%$ vs. $93.5 \%$ fusion rate $(p=0.709)$ and graft collapse incidence of $13.6 \%$ vs $4.3 \%(p=0.187)$ for autograft and allograft, respectively; however fusion took a longer time to occur in the allograft group. The number of levels fused per case did not have any significant effect on outcome measures. More recent level III studies ${ }^{6,7,9,10}$ using instrumentation to augment allograft constructs also reported high fusion rates, ranging from 91.9\% to $94.3 \%$. Other level III and level IV data similarly related favorable fusion outcomes with allograft use in the cervical spine.

Allograft use for posterior cervical fusion, especially occipito-cervical fusions has been evaluated in level III and level IV studies. ${ }^{5,6}$ Good fusion rates ranging from $89.9 \%{ }^{6}$ to $95 \%^{5}$ were reported.
Allografts in lumbar spine fusion

Twelve publications ${ }^{18-29}$ including two level $\mathrm{I}^{21,22}$ and four level $\mathrm{II}^{18,19,25,26}$ studies were found reporting the use of allograft in the lumbar spine. These can be broadly grouped according to use into lumbar interbody fusion or posterolateral fusion. In a prospective randomized study, Putzier et al. ${ }^{21}$ (Level I) evaluated the use of allogenic cancellous bone versus cancellous iliac crest autograft for instrumented monosegmental lumbar spondylodesis in combination with PEEK cages. The surgical technique described was circumferential, consisting of a single-stage anterior procedure followed by posterior instrumentation. Fusion was assessed using plain-films and CT scans for bone formation in the arthrodesed interbody spaces. The authors found no statistically significant differences in the radiological fusion rates between the two groups (85\% with autograft versus $80 \%$ with allograft) based on 12 month post-operative radiograph assessment $(\mathrm{k}=0.90)$. Clinical outcomes using the Oswestry low back pain Disability Index (ODI) also demonstrated no significant differences in allograft and autograft groups. In another level I study, Thalgott et al. ${ }^{22}$ reported that, compared to frozen femoral ring allografts (FRAs), use of freeze dried FRAs for circumferential instrumented lumbar fusion was associated with a higher likelihood of pseudarthrosis (radiographic fusion rates $65.38 \%$ vs. $76.67 \%$ respectively assessed by periodic $\mathrm{AP}$ and lateral radiographs and CT at final follow-up) ( $\mathrm{p}=$ 0.026). The clinical outcomes between the two groups did not differ significantly. A level III study by Wimmer et al. ${ }^{28}$ involved 94 patients with spondylolisthesis treated with anterior interbody fusion using either iliac crest autograft or femoral head allograft supplemented by pedicle screws posteriorly. A 92\% fusion rate was reported in the allograft group compared to $95 \%$ for autograft $(p>0.05)$. Four Level IV studies ${ }^{20,23,24,27}$ on lumbar interbody fusion, employing either femoral ring or femoral head allografts, similarly demonstrated high radiological fusion rates (ranging from 88 to $98 \%$ ).

For posterolateral lumbar fusion surgery, two Level II studies by $\mathrm{An}^{25}$ and Jorgenson et al. ${ }^{26}$ demonstrated inferior radiological fusion results for corticocancellous allografts (35 - 39.1\% fusion rates) compared to autologous iliac crest grafts (up to $80 \%$ ). 
However, two recent level II studies ${ }^{18,19}$ utilizing allografts in combination with bone marrow aspirate (BMA) reported fusion rates up to $80 \%{ }^{18}$ and equivalence with autologous iliac crest grafts. ${ }^{19}$

\section{Allografts in Deformity/Scoliosis/Paediatric spine}

No level I or level II studies were found describing the use of allografts in deformity correction surgery. Allograft use in combination with posterior segmental instrumentation was reported to have acceptable fusion rates (ranging from 70\% to $92.7 \%$ ) and seemed to be an efficacious and safe substitute for autologous bone in several level III 30,31 and level IV studies. ${ }^{32-36}$ In one study however, Demirkiran et al. ${ }^{36}$ reported high rates of pseudoarthrosis (13.3\%) in a series of 15 patients with long segment ( $>6$ level) posterior instrumented fusions, with an overall fusion rate of 86.7\% using allograft for instrumented posterior fusions alone. Murphy et al. ${ }^{35}$ showed the safe and effective use of allografts in paediatric subaxial spine surgery with fusion reported in $88 \%$, in their series of 18 patients.

\section{Allografts in Spine Trauma, Tumor and Infections}

In a prospective series of 36 patients Finkelstein et al. ${ }^{37}$ (level IV) reported that the use of cortical strut allografts along with instrumented stabilization was a safe and viable alternative to tri-cortical iliac crest autograft, in terms of radiological fusion outcomes (81\% radiologic fusion rate for allografts, no comparator group) for the treatment of thoracolumbar fractures. In another series of 41 patients with large anterior vertebral column defects resulting from various etiologies such as trauma, tumor and infection, Singh et al..$^{38}$ (level IV) found that long segment anterior structural allograft worked well in maintaining vertebral height and structural integrity. A radiological fusion rate of $97.5 \%$ was reported.

The use of structural allograft for the treatment of residual spinal deformity and collapse secondary to tuberculous osteomyelitis was investigated in three different studies (level IV) by Govender et al ${ }^{39-41}$ The authors concluded that femoral, fibular and humeral allografts were all suitable alternatives to autologous tricortical iliac crest and rib grafts in treating spinal defects, with reported radiological fusion occurring in $94.2 \%$ to $100 \%$ of patients. In a series of 47 patients with vertebral osteomyelitis, Schuster et al. ${ }^{42}$ (level IV) also concluded that the use of structural allografts in combination with aggressive tissue debridement and adjuvant antibiotic therapy was a safe and effective form of treatment.

\section{Evidence Summary for Allografts}

Use of allografts for cervical fusions is supported in published literature for both anterior (level I, II, III, IV data) and posterior cervical fusions (level III, IV data). The routine supplemental use of anterior cervical plates for instrumentation in recent studies, has resulted in a dramatic increase in fusion rates overall. For lumbar spine applications, the majority of published studies (including level I and II) reported good radiological and clinical outcomes for anterior interbody and circumferential fusions. However allograft use alone for instrumented posterolateral lumbar fusions is not well supported, with two level II studies reporting inferior fusion rates, although there were no differences in clinical outcomes. Allografts in combination with bone marrow aspirates have shown good fusion efficacy for posterolateral lumbar fusions in two recently published level II studies. For use in deformity correction, trauma, tumor and infections, the studies are supportive, although of lower quality evidence (mostly level III and IV).

\section{Demineralized bone matrix}

\section{(DBM)}

Demineralized bone matrix (DBM) is derived from human allograft bone. Acid extraction of the bone results in a product that consists of a combination of organic matrix proteins (osteoconductive) with small quantities of growth differentiation factors (osteoinductive). A variety of DBM preparations have been made commercially available in the form of powders, granules, gels, putties, and strips.

\section{DBM use in Cervical Spine}

No level I studies could be identified in this subgroup. A single level II prospective study by An et $\mathrm{al}^{43}$ evaluated the use of DBM (Grafton DBM ${ }^{\mathrm{TM}}$ ) in combination with allograft for cervical disc disease. In this study involving un-instrumented fusions, radiologic pseudarthrosis was found in $33.3 \%$ of treated 
cervical levels in the allograft-DBM group versus $22 \%$ of levels in the autograft group $(\mathrm{p}=0.23)$. Anteroposterior, lateral and flexion-extension radiographs taken 12 months after surgery were used to analyze fusion. A number of level IV studies ${ }^{44-47}$ reported acceptable to good fusion rates (ranging from $88.9 \%$ to $97 \%$ ) and comparable clinical outcomes using a combination of DBM and interbody cages for cervical fusion.

\section{DBM use in Lumbar fusion}

Reports evaluating the use of DBM in lumbar spine fusions are numerous. A total of thirteen articles ${ }^{48-60}$ (one level I ${ }^{48}$, two level II ${ }^{53,54}$, five level III ${ }^{49,50,56,59,60}$ and five level $\mathrm{IV}^{51,52,55,57,58}$ ) were identified in this subclass. In a level I prospective multicenter randomized clinical trial, Kang et al.$^{48}$ reported on the efficacy of a DBM preparation (Grafton $\mathrm{DBM}^{\mathrm{TM}}$ ) compared with iliac crest autograft for single-level posterior lumbar fusion. Arthrodesis rates evaluated using plain radiographs and computed tomographic scans at 6-month, 1-year, and 2-year time points were $86 \%$ for the DBM group versus $92 \%$ for the autograft group $(p=1.0)$. Higher physical function scores were observed in the DBM group at 2 year follow-up, although this also was not statistically significant. The authors concluded that fusion rates and clinical outcomes associated with DBM for lumbar fusion were comparable to the use of iliac crest autograft.

The role of DBM as a fusion extender in conjunction with autograft was investigated by Cammisa et al. ${ }^{54}$ (level II) in a 120 patient series undergoing instrumented posterolateral lumbar fusion. Iliac crest autograft was implanted on one side of the spine while a DBM (Grafton DBM ${ }^{\mathrm{TM}}$ ) and autograft composite was used on the contralateral side in the same patient. All subjects were scheduled for anteroposterior radiographs of the lumbar spine at 3,6,12,18, and 24 months. At 12, 18, and 24 months, lateral decubitus flexion-extension films also were included to confirm fusion integrity. After two years of follow-up, fusion rates of $52 \%$ on the DBM side and $54 \%$ on the iliac crest autograft side were observed. The overall percentage agreement for fusion status between sides reported was approximately $75 \%$, suggesting moderately strong statistical correspondence $(\mathrm{k}=0.51$, $\mathrm{p}<0.0001)$. In another level II prospective study,
Vaccaro et al. ${ }^{53}$ evaluated DBM (Grafton $\mathrm{DBM}^{\mathrm{TM}}$ ) use in instrumented posterolateral lumbosacral spine fusions. Nineteen patients had supplemental bone grafting with DBM putty enriched with aspirated bone marrow, 27 patients had DBM putty combined with iliac crest autograft, and the control group consisted of 27 patients with autograft. At 24 months after surgery, $63 \%$ of levels in the DBM and bone marrow group, $70 \%$ of levels in the DBM and iliac crest group, and 67\% in the ICBG group had radiological fusion as evaluated by anteroposterior, lateral and flexion-extension radiographs $(\mathrm{p}=0.875)$. The remaining studies in this sub-group (level III ${ }^{49,50,56,59,60}$ and $\mathrm{IV}^{51,52,55,57,58}$ ) similarly provide supportive data for the use of DBM as a graft expander in lumbar fusion surgery.

\section{DBM use in Scoliosis}

Two level III reports explored the use of DBM in scoliosis patients. In a retrospective study Weinzapfel et al. ${ }^{61}$ compared fusion rates between allograft bone and DBM (Grafton DBM ${ }^{\mathrm{TM}}$ ) following videoassisted thoracoscopic surgery for idiopathic scoliosis. Eighty-two percent of disc levels in the allograft group and $92 \%$ in the DBM group were rated as radiologically fused, suggesting superior results for DBM use in scoliosis. Percentage curve correction from before surgery to last follow-up was purportedly similar in both groups. Price et al. ${ }^{62}$ also related comparable fusion and failure outcomes for a composite of DBM and autologous bone marrow versus iliac crest autograft in adolescent idiopathic scoliosis.

\section{Evidence summary for DBM}

The bulk of the literature on demineralized bone matrix pertains to the lumbar spine, wherein DBM has been shown to be an effective bone extender, when used to augment the volume of autograft (across all evidence level studies). Reports on the use of DBM in the cervical spine along with PEEK cages similarly suggest that DBM is an acceptable alternative to autologous bone (level II, III and IV data). Data regarding the role of DBM in scoliosis is encouraging, although limited to two level III studies. Since demineralized bone matrices lack structural strength, they cannot be used independently in situations where biomechanical stability is required. Utilization of DBM for spine fusion has typically been in combi- 
nation with some form of structural bone substitute or interbody cage, with no clinical evidence supporting the use of DBM as a standalone substitute.

\section{Ceramics}

Ceramics constitute one of the most extensively studied groups of bone substitutes in spine surgery. Similar to their DBM counterparts, ceramics are mainly used as bone graft extenders in combination with autologous bone or bone marrow aspirates and interbody devices. Ceramics work by providing a scaffold for bone growth and are predominantly osteconductive. Additional favorable properties of ceramics include the biodegradable nature, feasibility of large scale production and ease of sterilization, nonimmunogenicity, and relative lack of toxicity. However the brittle nature and low shear strength of ceramic grafts limit their use as a standalone bone substitute. Beta-Tricalcium Phosphate ( $\beta$-TCP), Hydroxyapatite (HA), Calcium Sulphate and more recently Silicate-Substituted Calcium phosphate ( $\mathrm{Si}-\mathrm{CaP}$ ) and $\beta$ Calcium pyrophosphate ( $\beta$-CPP) are among the most notable ceramic scaffolds that have been studied for use in human spinal fusions.

\section{$\beta$-Tricalcium Phosphate ( $\beta$-TCP) $\beta$-TCP in the lumbar spine}

In a prospective randomized clinical study, Dai et al. ${ }^{63}$ (level I) reported on 62 patients with symptomatic degenerative lumbar spinal stenosis treated with single-level instrumented posterolateral lumbar fusion, with three years follow-up. Patients were randomly assigned to fusion with $\beta$-TCP $\left(\mathrm{BiLLu}^{\mathrm{TM}}\right)$ combined with local bone obtained from the decompression $(n=32)$ or autologous iliac crest graft $(n=30)$. There were no significant differences in recovery rates using the SF-36 and Japanese Orthopedic Association (JOA) scores at all time intervals. Standard $\mathrm{AP}$ and flexion-extension films were obtained at 3, 6, 12 and 24 months, and successful radiographic fusion was documented in all patients in both treatment groups.

Yamada et al.$^{64}$ conducted a prospective comparative study (level II) in 61 consecutive patients undergoing decompressive laminotomy and single level instrumented posterolateral fusion. Constructs of hybrid bone grafts $\left(\beta\right.$-TCP $\left[\right.$ Osferion $\left.^{\mathrm{TM}}\right]+$ autologous iliac crest bone strips + autologous bone marrow aspirates) were placed on one side of the inter-transverse gutter in all patients. Autologous local bone graft harvested during the laminotomy was placed on the contralateral side as control. Fusion rates assessed with both radiographs and CT scans was higher for the hybrid bone graft side (68.9\% at 6 months, $83.6 \%$ at 1 year, $93.5 \%$ at 2 years) than that for the local bone graft side (49.2\% at 6 months, $75.4 \%$ at 1 year, $89.1 \%$ at 2 years) with a significant difference at 6 months after surgery $(\mathrm{p}<0.05)$. In 2013, Kong et al..$^{65}$ (level II) reported that the posterolateral fusion rate, using a mixture of $\beta$-TCP (PolyBone ${ }^{\mathrm{TM}}$ ) and local bone, was lower than that for local bone alone (57.1\% vs $73.8 \%)$ at 12 months follow-up $(\mathrm{p}=0.092)$. Lumbar anteriorposterior (AP) and lateral radiograph imaging was done immediately postoperative and at 1, 3, 6 and 12 months. Computed tomography (CT) follow up was also done immediately postoperative and at 12 months. The authors postulated that $\beta$-TCP seemed to be counterproductive for fusion in relation to the same amount of autologous bone. A similar opinion was echoed by Thaler et al..$^{66}$ in a series of 34 patients (level IV) using $\beta$-TCP $\left(\right.$ ChronOS $\left.^{\mathrm{TM}}\right)$ in combination with autologous bone marrow aspirate for instrumented posterior lumbar interbody fusion (PLIF). The authors recommended avoiding the use of $\beta$ TCP due to high pseudoarthrosis rates. In contrast, five level IV studies ${ }^{67-71}$ reported acceptable results with the use of $\beta$-TCP in combination with autologous bone marrow aspirate for lumbar fusions.

\section{$\beta$-TCP in the cervical spine}

No published level I studies reported on the use of $\beta$ TCP in cervical fusions. By way of a level II prospective study, Dai et al. ${ }^{72}$ concluded that interbody fusion cages containing $\beta$-TCP following one- or twolevel discectomy proved to be an effective treatment for cervical spondylotic radiculopathy and/or myelopathy, with successful fusion seen in all patients at 6 months follow-up ( $<<0.05)$, as evaluated using standard AP and lateral flexion-extension radiographs. In a retrospective cohort review, Sugawara et al. ${ }^{73}$ (level III) reported on the use of $\beta$-TCP (Osferion $^{\mathrm{TM}}$ ) (93 segments in 57 patients) compared to Hydroxyapatite (72 segments in 48 patients) packed in cylindrical titanium cages for ACDF procedures. 
The complete fusion rate at 6 months and 1 year was significantly superior in the $\beta$-TCP group ( $46 \%$ at 6 months and $69 \%$ at 1 year) than in the HA group (24\% at 6 months and $49 \%$ at 1 year) $(\mathrm{p}<0.05)$, and the rates were similar in both groups at two years. Other available Level III ${ }^{74}$ and level IV $^{75,76}$ studies report good efficacy and satisfactory outcomes with $\beta$-TCP use when compared to autologous bone grafts.

$\beta$-TCP use in scoliosis

Two level I publications ${ }^{77,78}$ evaluating the application of $\beta$-TCP in scoliosis surgeries were identified. Lerner et al. ${ }^{77}$ randomized 40 patients with adolescent idiopathic scoliosis (AIS) into two treatment groups undergoing corrective posterior instrumentation; both groups were similar in terms of patient-related and procedure factors. In 20 patients, iliac crest bone graft (ICBG) harvesting was performed whereas the other half received $\beta$-TCP $\left(\right.$ Vitoss $^{\mathrm{TM}}$ ) augmenting local bone graft. Patients were observed clinically and radiologically for a minimum of 20 months postoperatively, with a mean follow-up of four years. Average curve correction was reported at $61.7 \%$ in the $\beta$-TCP group and $61.2 \%$ in the ICBG group at hospital discharge $(\mathrm{p}=0.313)$ and $57.2 \%$ and $54.3 \%$, respectively, at follow-up $(\mathrm{p}=0.109)$. The authors concluded that the use of $\beta$-TCP as extenders of local bone graft yielded results equivalent to ICBG in the posterior correction of AIS. Delecrin et al. ${ }^{78}$ also reported favorable results for the use of porous biphasic calcium phosphate ceramic blocks comprised of $\beta$-TCP and hydroxyapatite $\left(\right.$ Triosite $^{\mathrm{TM}}$ ) in 58 patients with idiopathic scoliosis. In a level II study, Muschik et al. ${ }^{79}$ evaluated the utility of $\beta$-TCP $\left(\mathrm{ChronOS}^{\mathrm{TM}}\right)$ in a granular form to achieve dorsal spondylodesis in 28 patients with AIS. Posterolateral grafting was performed, using either autograft bone mixed with allograft bone $(\mathrm{n}=19)$ or autograft bone mixed with $25 \mathrm{~g}$ TCP $(n=9)$. Radiographically assessed fusion occurred within $6 \pm 1$ months in both groups $(\mathrm{p}<0.87)$, with no pseudoarthrosis observed. The authors inferred that the use of $\beta$-TCP appeared to be a valuable alternative to allograft for deformity surgeries where large amounts of bone are required.

Evidence summary for $\beta$-TCP

Data on $\beta$-TCP use for lumbar spine fusions is inconclusive in view of conflicting results reported across all evidence levels of studies. This is in contrast to its application in cervical spine where all studies report good clinical and fusion outcomes. Similarly, two level I and a single level II study endorse the use of $\beta$ TCP for deformity correction in adolescent idiopathic scoliosis.

\section{Hydroxyapatite (HA)}

Hydroxyapatite is a naturally occurring mineral found in bones and is estimated to contribute up to $50 \%$ of the bone by mass. ${ }^{80}$ Coralline hydroxyapatite, as the name suggests, is synthesized from sea corals. The material properties of hydroxyapatite are similar to other ceramics; however, compared to the more porous tricalcium phosphate scaffolds, HA products are relatively inert and take longer for biodegradation and resorption. ${ }^{81}$

\section{Hydroxyapatite (HA) in Lumbar spine}

Level I evidence on the use of HA in cases of intertransverse posterior lumbar fusion does not conclusively support its use over autologous iliac crest bone graft. Korovessis et al. ${ }^{82}$ compared coralline hydroxyapatite (Pro Osteon $\left.{ }^{\mathrm{TM}}\right)(\mathrm{n}=19$; group $\mathrm{A})$, iliac bone graft $(n=18$; group $B)$ or both $(n=20$; Group $C)$ in the setting of instrumented posterolateral and lumbosacral fusions for patients with degenerative lumbar spinal stenosis. Plain radiographs (standing AP and lateral views, supine oblique right and left, and sitting frontal and lateral bending views) were obtained preoperatively and at 3, 6, 12, 24 and 48 months postoperatively. CT scans were also performed preoperatively and at 12 and 24 months postoperatively to evaluate facet joint arthrodesis. Radiological fusion was achieved at 1 year postoperatively in all groups and vertebral segments. In a prospective case control study involving 58 patients with degenerative spinal stenosis, Hsu et al. ${ }^{83}$ (level II) compared coralline hydroxyapatite (CHA) and laminectomy-derived bone as adjuvant graft materials for posterolateral lumbar fusions. Patients were allocated into three groups: laminectomy bone and ICBG (group 1, n = 20), CHA and ICBG (group 2, n $=19$ ), and laminectomy bone and CHA (group 3, $\mathrm{n}=$ 19); the respective graft materials were placed in either the right or left inter-transverse space. The best radiological fusion rates were obtained with pure autologous iliac crest graft (95\%). After 6 months, CHA

Downloaded from http://ijssurgery.com/ by guest on April 26, 2023 
produced a comparable result to laminectomyderived bone when combined with iliac crest autograft (group 2) $(\mathrm{p}=0.097)$. However the combination of laminectomy bone with CHA (group 3) failed to yield a satisfactory fusion rate (57.9\%) up to one year after surgery if no autologous iliac crest graft was added $(\mathrm{p}=0.0217)$. At 1 year postoperatively, the fusion rate difference between groups 1 and 2 remained insignificant $(\mathrm{p}=0.3376)$. For Group 3 , the fusion rate (57.9\%) was markedly lower than that in Groups 1 and 2 (90.0 and 78.9\%, respectively). The difference was statistically significant $(\mathrm{p}=0.0217)$ between Groups 1 and 3, but not between Groups 2 and $3(\mathrm{p}=0.1627)$. In a level III retrospective study, Hyoungmin et al. ${ }^{84}$ concluded that porous hydroxyapatite bone chips (Bongros $\mathrm{HA}^{\mathrm{TM}}$ ) were valuable bone graft extenders in PLIFs when used in conjunction with local bone. Three other level IV studies ${ }^{58,85,86}$ also supported the use of hydroxyapatite as an effective option in combination with other bone graft substitutes such as allograft and autograft.

Hydroxyapatite (HA) in the Cervical spine

A single level I study demonstrated that coralline hydroxyapatite was structurally inferior to iliac crest bone for cervical interbody fusion, although clinical results and fusion rates were similar. In this study by McConnell et al ${ }^{87}$, graft fragmentation occurred in $89 \%$ of the hydroxyapatite grafts versus $11 \%$ of the autograft $(\mathrm{p}=0.001)$. Plain AP and lateral radiographs at periodic intervals and CT images for the final status were used to evaluate interbody fusion rates. Significant graft settling was also reported in $50 \%$ of the HA grafts, as compared to $11 \%$ of the autograft patients $(p=0.009)$. However four level IV studies (using $\mathrm{CHA}^{88}$, porous $\mathrm{HA}^{89}$, porous/dense HA composite $^{90}$ and nano-HA/polyamide cages ${ }^{91}$ ) reported good results (fusion rates ranging from $92.50 \%$ to $100 \%$ ) and concluded that HA was an effective alternative to autologous iliac crest graft.

Hydroxyapatite (HA) in Scoliosis

A single case series of 27 patients (level IV) by Mashoof et al. ${ }^{92}$ was identified, concluding that coralline hydroxyapatite was a safe, biocompatible, and effective means of augmenting autogenous bone graft in the treatment of idiopathic adolescent scoliosis with posterior spinal fusion. All patients achieved solid fusion at an average follow-up of 27 months in their series.

\section{Evidence summary for hydroxyapatite (HA)}

Hydroxyapatite (HA) use in lumbar and cervical spine fusions was not well endorsed by higher evidence level studies, although level III and level IV studies reported good outcomes. Data on the application of HA to scoliosis surgery is also limited to a single case series. Differences in the porosities of ceramic bone extenders may account for these conflicting results in clinical studies. Of note, Wang et al. ${ }^{93}$ demonstrated with a clinical study that the porosity of ceramics such as $\beta$-TCP had a statistically significant effect on fusion rates, with less porous formulations producing better fusion outcomes. Data such as these may be equally applicable to other forms of ceramic such as hydroxyapatite. The differences in porosities and compositions of commercially available hydroxyapatite products make generalization across the group difficult.

\section{Calcium Sulphate}

Literature on calcium sulphate products is limited to their use in lumbar fusion surgeries, with two level $\mathrm{I}^{94,95}$, one level $\mathrm{II}^{96}$, and one level $\mathrm{III}^{97}$ studies included. Niu et al. ${ }^{94}$ (level I) evaluated fusion rates using autogenous laminectomy bone chips and calcium sulfate pellets (Osteoset ${ }^{\mathrm{TM}}$ ) augmented with bone marrow aspirates in a prospective randomized study of single-level lumbar posterolateral fusions involving 43 patients. Autologous ICBG was placed on one side in the posterolateral gutter in all patients as a control, and on the other side an equal quantity of laminectomy bone chips mixed with BMA (group 1, $\mathrm{n}=21$ ) or calcium sulfate pellets soaked in BMA (group 2, n=22) were used. For the 21 patients in group 1, 18 (85.7\%) exhibited bone fusion on the test side, and 19 (90.5\%) presented evidence of fusion (assessed by follow-up radiographs and/or computed tomograms) on the control side. Thus, the test side with laminectomy bone chips and BMA achieved a fusion rate similar to that on the control side ( $\mathrm{p}>$ $0.05)$. For the 22 patients in group 2, 20 (90.9\%) exhibited bone fusion on the control side whereas only $10(45.5 \%)$ demonstrated complete fusion on the test side $(\mathrm{p}<0.05)$, where calcium sulfate and BMA was applied. The authors concluded that Osteoset ${ }^{\mathrm{TM}}$ was 
significantly inferior to ICBG despite the addition of osteoinductive BMA. In contrast, Alexander et al..$^{95}$ found that calcium sulfate pellets plus local decompression bone provided equivalent results compared to autologous ICBG in his preliminary paper on a prospective randomized study sample. In a level II prospective study, Chen et al..$^{96}$ also reported equivalent fusion outcomes for iliac crest bone graft and autograft laminectomy bone with calcium sulfate pellets in 74 patients who underwent one-level (87.2\% on test side vs. $89.7 \%$ on control side) or two-level lumbar fusions $(82.9 \%$ on test side vs. $85.7 \%$ on control side) $(\mathrm{p}>0.05)$. Comparable results were reported by Chang et al. ${ }^{97}$ in a level III retrospective study of 66 patients who underwent single level posterolateral lumbar fusions with Osteoset ${ }^{\mathrm{TM}}$.

Evidence summary for Calcium Sulphate

There are discrepancies between the two published level I studies on calcium sulphate use for lumbar spinal fusion, although both utilized the same preparation $\left(\right.$ Osteoset $\left.^{\mathrm{TM}}\right)$. These differences are especially difficult to interpret in light of the fact that the study by Niu et al. ${ }^{94}$ utilizing osteogenic bone marrow aspirates, which should have augmented fusion rates, instead refuted the effectiveness of calcium sulphate pellets. Other studies (level II, III and IV) however are in support of the use of calcium sulphate as a bone graft extender in combination with local autologous bone obtained from decompression.

\section{Silicate substituted Calcium Phosphate (Si-CaP)}

Silicate substituted calcium phosphates are a novel sub-class of ceramic bone substitutes which, in addition to exhibiting osteoconductive properties, are purported to be osteoinductive as well. This newer generation ceramic material, as the name implies, is prepared by partially substituting silicate for phosphate in a controlled manner. This substitution is typically $0.8 \%$ by weight for the commercially available product Actifuse ${ }^{\mathrm{TM}}$. The presence of silicate increases the negative charge of the ceramic scaffold, which is hypothesized to attract more osteoblasts to the material surface, thus conferring osteoinductive effects. ${ }^{98}$ Silicate-substituted calcium phosphate (Si$\mathrm{CaP}$ ) has also been shown to exhibit an increased in vivo resorption rate compared to the more traditional hydroxyapatite ceramics. ${ }^{99}$
Silicate substituted calcium phosphate (Si-CaP) in lumbar spine and cervical spine

Level I and level II studies evaluating the efficacy of $\mathrm{Si}-\mathrm{CaP}$ versus autologous bone grafts are currently lacking, though two level I studies ${ }^{100,101}$ comparing Si$\mathrm{CaP}$ with rhBMP were identified. Level IV retrospective studies by Jenis et al. ${ }^{102}$ and Nagineni et al. ${ }^{103}$ reported fusion rates from $76.5 \%$ to $90 \%$ with the use of Si-Cap in cervical and lumbar fusion procedures.

Silicate substituted calcium phosphate ( $\mathrm{Si}-\mathrm{CaP}$ ) in scoliosis Harshavardhana et al. ${ }^{104}$ in a series of 35 AIS patients (level IV), reported no evidence of pseudarthrosis with the use of Si-CaP $\left(\right.$ Actifuse $^{\mathrm{TM}}$ ) at 2.9 years of average follow up. No complications were reported in the study. Another level IV publication by Lerner et al. ${ }^{105}$ on the use of SiCap Actifuse $^{\mathrm{TM}}$ ) for the posterior correction of AIS demonstrated good results in terms of curve correction maintenance, formation of solid fusion masses (100\% of cases), and improvements in Visual Analog Scale (VAS) and SRS-22 (Scoliosis Research Society Questionnaire) scores.

\section{Evidence summary for Si-CaP}

Though level IV data support the use of $\mathrm{Si}-\mathrm{CaP}$ as a viable alternative to autograft in degenerative lumbar spine fusion and scoliosis surgery, level I studies directly evaluating comparability to autologous bone grafts are not presently available.

\section{$\beta$-calcium pyrophosphate ( $\beta$-CPP)}

Another novel ceramic substitute, $\beta$ calcium pyrophosphate ( $\beta$-CPP) has shown promising results in animal studies in terms of fusion rates and rapid incorporation and resorption characteristics. ${ }^{106}$

$\boldsymbol{\beta}$-calcium pyrophosphate $(\boldsymbol{\beta}-\mathrm{CPP})$ in lumbar spine A single published report ${ }^{107}$ (level II) was found describing the use of this substitute for short segment lumbar fusions. In this prospective, case matched study, the authors concluded that $\beta$-CPP combined with autograft was as effective as autologous bone for instrumented posterolateral interbody fusions. Radiographic evaluation of fusion was done using periodic radiographs and three dimensional thin cut $(1 \mathrm{~mm})$ CT images at 12 months postoperatively. The reported fusion rates were $87.0 \%$ in the $\beta$-CPP group and $89.1 \%$ in the autograft group, which were not signifi- 
cantly different.

Evidence summary for $\beta$-calcium pyrophosphate

Although early results suggest efficacy similar to autograft, current data is inadequate to draw conclusions.

\section{Bone morphogenic proteins}

\section{(BMPs)}

No class of bone substitutes/bone graft extenders has been as extensively studied and published as BMPs. Bone morphogenic proteins (BMPs) are osteoinductive molecules belonging to the transforming growth factor beta (TGF- $\beta$ ) superfamily of proteins. Of the more than 20 types of BMPs described, BMP- 2 and BMP-7 (also known as Osteogenic protein-1, or OP-1), in their recombinant forms (rh), are the most widely used BMPs in clinical practice. Since BMPs are soluble proteins and may readily diffuse into the surrounding tissues, away from the site of application, they are used in combination with carriers to maintain effective concentrations at the intended fusion sites. Though efforts to identify the ideal carrier are ongoing, absorbable collagen sponges (ACS) and compression resistant matrix (CRM) are frequently used. Autologous and allogenic bone grafts, ceramics, DBMs and polylactic acids are other substrates that have been utilized for rhBMP delivery.

Recombinant Bone Morphogenic Protein-2 (rhBMP-2) Recombinant BMP-2 has been studied in diverse settings such as degenerative lumbar and cervical spinal fusions, deformity correction, and pediatric spinal fusions as well as in osteomyelitic conditions of the spine. Recombinant BMP-2 in combination with an absorbable collagen sponge (Infuse ${ }^{\mathrm{TM}}$ ) has FDA approval only for anterior lumbar interbody fusions (ALIF) when used within a titanium tapered cage. ${ }^{108}$ All other uses of rhBMP-2 are currently physician directed off-label applications.

Recombinant Bone Morphogenic Protein-2 (rhBMP-2) in Lumbar spine

A total of 33 studies (seven level I ${ }^{109-115}$, eight level II116-123, eight level III ${ }^{124-131}$, nine level IV ${ }^{132-140}$, one unclassified $^{141}$ ) were identified pertaining to rhBMP-2 use in the lumbar spine alone. The sheer volume of literature on rhBMP-2 reflects its acceptance and popularity as a widely used fusion enhancer, as well as the controversial nature of this compound associated with specific complication profiles.

There are several level I and level II studies describing rhBMP-2 usage in anterior lumbar fusion applications. Burkus et al. ${ }^{114}$ conducted a prospective, randomized, multicenter study (level I) involving $131 \mathrm{pa}-$ tients to evaluate the safety and efficacy of rhBMP-2 as a replacement for autogenous ICBG in anterior lumbar spinal arthrodesis. The average ODI scores, SF-36 physical component summary scores, and lowback and leg-pain scores were significantly better in the study group $(\mathrm{p}<0.05)$. Significantly higher fusion rates ( $99 \%$ vs. $76 \%$ ) were also reported in the study group ( $\mathrm{p}<0.001)$, assessed with radiographs and CT. Slosar et al. ${ }^{118}$ reported a $100 \%$ fusion rate at 24 months follow-up after anterior lumbar interbody fusions using rhBMP-2 and femoral ring allograft. Similarly high fusion rates (94.5 - 100\%) were reported by Burkus et al. in two level II studies ${ }^{121,122}$ in the context of rhBMP-2 use for anterior lumbar interbody fusions.

There are numerous level I studies describing usage of rhBMP-2 in posterior lumbar applications. After a level I randomized controlled study, Michielsen et al. ${ }^{109}$ reported results in 40 patients treated with an instrumented single-level posterior lumbar interbody arthrodesis. Interbody arthrodesis was performed using polyether-ether-ketone (PEEK) cages which were filled with $8 \mathrm{mg}$ of rhBMP-2 in the study group and $2.5 \mathrm{~mL}$ of autologous bone in the control group. CT scans of the arthrodesed segments were made at three, six, and twelve months postoperatively, as well as bone density measurements. There was a significant difference between the groups with respect to interbody healing on bone densitometry analysis at three, six, and twelve months $(\mathrm{p}=0.021, \mathrm{p}=0.004$, and $\mathrm{p}=0.014$, respectively). Fusion on CT scan was ultimately achieved in all patients. The authors also found no significant differences in clinical results (VAS, ODI, and SF-36) between the groups at each postoperative visit. In another level I study wherein 197 patients underwent 1 or 2 level instrumented posterolateral lumbar fusion, Hurlbert et al. ${ }^{110}$ report-

Downloaded from http://ijssurgery.com/ by guest on April 26, 2023 
ed significantly higher radiological fusion rates (assessed via plain radiographs) in patients treated with high doses rhBMP-2 (42 mg/level) compared to those who received autograft (94\% vs. $69 \%$ respectively) $(\mathrm{p}=0.007)$ at 4 years of follow-up. However, there were no significant improvements in clinical outcomes in the rhBMP-2 group. In two independent level I studies, ${ }^{111,113}$ Dimar related significantly higher fusion rates for patients in rhBMP-2 groups (using AMPLIFY $^{\mathrm{TM}}, 40 \mathrm{mg}$ rhBMP-2) treated with instrumented posterolateral fusions versus controls in which autologous ICBG was used $(96 \%$ for the rhBMP group vs. $89 \%$ with ICBG, $\mathrm{p}=0.014$, and $88 \%$ with rhBMP vs. $73 \%$ in ICBG group, $p=0.051$ ). Clinical outcomes in all groups improved significantly overall; however the increment in outcome measures was not statistically superior for the rhBMP-2 groups in either study. Other level I studies by Glassman et al. ${ }^{112}$ and Boden et al. ${ }^{115}$ comparing rhBMP-2 to AICBG for posterolateral lumbar fusions reported higher fusion grades, with fusion rates approaching $100 \%$ in the study groups.

Eight level II studies on the use of rhBMP-2 in lumbar spine were identified and reviewed. Dawson et al. ${ }^{116}$ performed a prospective, randomized, multicenter pilot study investigating the use of rhBMP-2 on an absorbable collagen sponge (12 mg rhBMP- 2 dose) combined with a ceramic-granule bulking agent as a replacement for autogenous ICBG in single level instrumented posterolateral lumbar arthrodesis. By 24 months, $95 \%$ of patients in the investigational group compared with $70 \%$ in the control group had documented fusion (assessed with radiographs and CT scan) $(p=0.120)$. Significant improvements in clinical outcome measures were also reported in both groups. The authors concluded that the combination of an osteoinductive agent with an osteoconductive matrix may be an effective replacement for autograft in instrumented single-level PLIF. Similarly Katayama et al. ${ }^{117}$ concluded that rhBMP-2 can be used as the sole source of osteogenesis with success equivalent to an autologous graft for posterolateral lumbar fusions ( $82 \%$ fusion rate for rhBMP-2 compared to $91 \%$ for autologous bone) after a study involving 11 patients who underwent posterolateral L4-5 fusions. In another level II study, Singh et al. ${ }^{119}$ reported an overall 97\% fusion rate in the rhBMP-2 group (12 mg dose) compared to a 77\% fusion rate with ICBG alone $(\mathrm{p}<0.05)$ for instrumented posterolateral fusions. A prospective non-blinded trial (level II) involving 67 patients who underwent PLIF using two cylindrical threaded fusion cages was conducted by Haid et al. ${ }^{120}$ Study participants were randomly assigned to one of two groups: investigational $(\mathrm{n}=34)$, who received rhBMP-2 on an absorbable collagen sponge (4-8 $\mathrm{mg}$ dose), and the control group ( $\mathrm{n}=33)$, who received autologous ICBG. Radiographs and CT scans were used to evaluate fusion at 6,12 and 24 months. At the last follow up, the $92.3 \%$ fusion rate in the investigational group was higher than that of the control group at $77.8 \%$, although this result was not statistically significant.

Multiple level III and level IV studies have been published regarding rhBMP-2 use for lumbar interbody fusions performed with the anterior (ALIF) $)^{139}$, transforaminal (TLIF) ${ }^{124-126,131}$ and posterior (PLIF) ${ }^{124}$ approaches as well as postero-lateral (PLF) $)^{128-130}$ and axial (AxiaLIF) ${ }^{127}$ techniques. Almost all of these reports supported the efficacy of rh-BMP-2 for increasing reliable fusion rates. Recent Level III studies by Adams et al. ${ }^{124}$, Gerszten et al. ${ }^{127}$ and Lee et al. ${ }^{128}$ however failed to document any significant differences in fusion rates with or without the use of rhBMP-2. In fact, after a retrospective cohort study Adams et al. ${ }^{124}$ concluded that rhBMP-2 may unnecessarily increase the risk of complications in routine PLIF and TLIF procedures .

\section{Recombinant Bone Morphogenic Protein-2 (rhBMP-2) in Cervical spine}

Recombinant BMP-2 applications in the cervical region can be broadly grouped into anterior and posterior cervical fusions.

Anterior cervical fusion

Baskin et al. ${ }^{142}$ (level I) compared the safety and effectiveness of Infuse $^{\mathrm{TM}}$ (rhBMP-2 / ACS) with AICBG placed inside a fibular allograft in a prospective, randomized, clinical pilot trial of anterior cervical discectomy with instrumented interbody fusion. At 24 months follow up, the study group showed mean improvement in neck disability index (NDI) and arm pain scores superior to that of the control group $(\mathrm{p}=0.03)$. One-hundred percent fusion rates 
were reported in both groups at 6,12 and 24 months follow up, assessed with radiographs and CT scans. Buttermann et al. ${ }^{143}$ (level II) also concluded that ACDF performed with rhBMP-2 combined with allograft (0.9 mg BMP per level) was as effective as iliac bone graft in terms of clinical outcomes and fusion rates in a prospective cohort study. Both the study and the control group had similar improvement in all outcome scales (VAS pain, pain drawing, ODI, pain medication use, and opinion of treatment success) and neurological recovery over the 2- to 3-year follow-up period. Level IV studies by Khajavi et al. ${ }^{144}$, Tumialan et al. ${ }^{145}$, Boakye et al. ${ }^{146}$ also supported rhBMP-2 use for ACDF.

Posterior cervical fusion

Yan $\mathrm{L}^{147}$ recently reported on a prospective, randomized trial (Level II) for the use of ICBG plus rhBMP-2/ACS (Infuse ${ }^{\mathrm{TM}}$ ) vs. ICBG alone in 140 patients who underwent instrumented posterior fusion for the treatment of atlantoaxial instability. The fusion rate was $82.4 \%$ ( 56 of 68 ) in the rhBMP-2/ACS group and 78.7\% (52 of 66) in the ICBG group ( $\mathrm{p}=$ 0.782 ). Fusion evaluation was done by CT scans performed using 1-mm slices with coronal and sagittal reconstructions. Mean fusion time was 11 days shorter in the rhBMP-2/ACS group than in the ICBG group $(p=0.034)$. The rest of the data on rhBMP-2 use in posterior cervical fusions is limited at present to four level IV studies, ${ }^{148-151}$ all of which reported good to excellent fusion rates (82.8\% to $100 \%)$ and patient outcomes, mostly pertaining to its application to occipito-cervical fusion.

Recombinant Bone Morphogenic Protein-2 (rhBMP-2) for deformity correction surgery

Two level II ${ }^{152,153}$, two level III ${ }^{154,155}$ and one level IV ${ }^{156}$ studies investigating the efficacy of rhBMP-2 for adult spinal deformity correction were found. All groups related reliable fusion rates with rhBMP-2, ranging $93.5 \%$ to $100 \%$, suggesting equivalence to autologous iliac crest bone. A level III study by Kim et al. ${ }^{154}$ further concluded that rhBMP-2 is in fact superior to ICBG in achieving fusion in long constructs for adult spinal deformity.
Recombinant Bone Morphogenic Protein-2 (rhBMP-2) for pediatric spinal surgery

Three level IV studies ${ }^{157-159}$ on the application of rhBMP-2 described excellent outcomes (100\% fusion rates), and supported rhBMP-2 as a successful adjunct to fusion in pediatric patients. However, the complication profile of BMP in this patient population seems to differ from that in adults and is yet to be completely understood.

Recombinant Bone Morphogenic Protein-2 (rhBMP-2) for spinal osteomyelitis

The use of rhBMP-2 in the treatment of pyogenic vertebral osteomyelitis is a relatively novel application. The safety and efficacy of rhBMP-2 in this clinical context is supported by three level IV studies. $^{160-162}$

Evidence Summary for rhBMP-2

Data of all evidence levels and all areas of application in cervical and lumbar spine fusion support the use of rhBMP-2 for obtaining a predictable fusion outcome and comparable efficacy to the gold standard autologous ICBG. Data on its use in pediatric spinal fusions and vertebral osteomyelitis, though promising, is presently limited and from lower quality studies.

Recombinant Bone Morphogenic Protein-7 (OP-1) Osteogenic Protein-1, also known as rhBMP-7, is the only other member of the BMP family whose clinical application has been studied and published in human subjects. This product is available commercially as putty consisting of recombinant OP-1 (rhOP-1) with type I bovine collagen matrix and sodium carboxymethyl cellulose (CMC) as an additive, to be reconstituted with $0.9 \%$ sterile saline solution. In 2004, the US-FDA granted approval of OP-1 putty for humanitarian device exemption (HDE) application as an alternative to autograft in compromised patients requiring revision posterolateral (inter-transverse) lumbar spinal fusions.

Osteogenic Protein 1 (OP-1) in lumbar spine

Delawi et al. ${ }^{163}$ in a prospective randomized study (level 1) evaluated OP-1 for single level instrumented posterolateral fusion surgery for degenerative or isthmic spondylolisthesis. 119 patients undergoing 
surgery were randomized 1:1 for bone-grafting (59: ICBG group and 60: OP-1 group). The primary outcome measures were available and evaluated for 113 (56: ICBG group and 57: OP-1 group) of the 119 patients at one year, consisting of a combination of clinical outcomes and evidence of fusion as determined on CT scans. Non-inferiority was not demonstrated in the OP-1 group ( $40 \%$ success rate versus $54 \%$ in the ICBG group) in view of lower rate of fusion in the OP-1 group (54\% in the OP-1 group versus $74 \%$ in the ICBG group, $p=0.03$ ). This was in contrast to the results reported in a previous prospective randomized pilot study involving 36 patients, by the same group of authors. ${ }^{164}$ Fusion rates reported in this study were $63 \%$ in the OP-1 group and 67\% in the autograft group $(\mathrm{p}=0.95)$, with no significant differences in Oswestry scores between the two $(\mathrm{p}=0.56)$. The authors previous conclusions that OP-1 combined with locally obtained autograft was a safe and effective alternative for iliac crest autograft was overturned in the newer study and it was asserted that OP-1 cannot be recommended in instrumented posterolateral lumbar fusion procedures.

Vaccaro et al. ${ }^{165,166}$ reported long term (4 year) outcomes with the use of OP-1 for non-instrumented posterolateral fusions in two independent level I studies, and OP-1 was found equivalent to autograft in terms of safety and efficacy in both. In one of those studies ${ }^{165}$ involving 335 patients with degenerative spondylolisthesis and spinal stenosis, a fusion rate of $74.8 \%$ for the OP-1 group was obtained compared to $77.4 \%$ for the autograft group. Fusion assessment was done by AP and lateral flexion extension radiographs and CT scans. The results were clinically comparable and not significantly different $(\mathrm{p}=0.852)$. In another level I prospective randomized study, Kanaya$\mathrm{ma}^{167}$ concluded that OP-1 reliably induced new bone formation, even without autogenous bone graft, but that the fusion rate was not encouraging. The investigation included surgical exploration and histologic assessment of fusion masses. In the OP-1 group radiological fusion was seen in $77.77 \%$ of the cases, whereas histological assessment of fusion mass in the patients in this group revealed a fusion rate of 57.1\%. In the control group where local autograft mixed with ceramic bone substitute was used, a 90\% radiological fusion rate and $77.77 \%$ histological fusion rate was re- ported. The authors suggested that some modification of either the surgical technique or the carrier may be required for extensive use of OP-1 in instrumented posterolateral lumbar fusion. Furlan et al. ${ }^{168}$ reported good fusion rates (80\%) and improved health related quality of life (HRQOL) outcomes in a level III study using OP-1 and autograft in 30 patients with high risk of spinal pseudarthrosis. The data consisted of cases of lumbar or lumbosacral fusions as well as cervical and occipitocervical fusions for high risk cases such as previous failed fusions, rheumatoid arthritis, systemic lupus erythematosus, MaroteauxLamy syndrome, ankylosing spondylitis, steroid use, immunosuppression, heavy smokers and osteopenic or osteoporosis. Level IV publications on a pilot study by Vaccaro et al..$^{169-171}$ support the safety of OP-1 putty when used as an adjunct to autogenous iliac crest bone graft in uninstrumented posterolateral fusions for degenerative spondylolisthesis. However these studies did not demonstrate improved efficacy of OP-1 combined with autologous bone as compared to autologous bone graft alone.

\section{Evidence Summary for rhBMP-7 (OP-1)}

Recently published level I studies suggest provide conflicting data on OP-1 compared to autologous bone grafts in terms of fusion rates and clinical patient outcomes for use in posterolateral lumbar fusions. Of note, rhBMP-7 (OP-1) has only been studied for posterolateral lumbar fusions. Compared to rhBMP-2, the use of rhBMP-7 for other lumbar spine procedures (e.g. ALIF, PLIF, TLIF, MIS) has not been investigated in clinical studies. Data on use in cervical fusions evaluating efficacy as a fusion extender is currently lacking.

\section{Autologous growth factors (AGF)}

This group consists of molecules such as Platelet derived growth factors (PDGF) and Transforming growth factor- $\beta$ (TGF- $\beta$ ) which have been shown to have mitogenic effects on fibroblasts, osteoblasts, and mesenchymal cells. ${ }^{172}$ They are obtained from the buffy coat layer formed after centrifugation of whole blood, which is rich in platelets and white cells. The use of these compounds in combination with autolo- 
gous bone (either iliac crest or locally derived), allograft or ceramics has been studied in spine fusion procedures.

Autologous growth factors (AGF) use in lumbar spine In a prospective randomized trial (level I) involving 40 patients, Sys et al. ${ }^{173}$ studied the application of platelet-rich plasma (PRP) for single level posterior lumbar interbody fusion procedures. The authors reported that adding PRP to autologous bone in posterior lumbar interbody fusion did not lead to a substantial improvement or deterioration when compared to autologous bone alone. There was no difference between both groups in interbody healing on CT-scan reconstructed images at 3,6 , and 12 months $(\mathrm{p}=0.741, \mathrm{p}=0.663, \mathrm{p}=0.951)$. Acebal-Cortina ${ }^{174}$ (level II) performed a prospective non-randomized study on the use of autologous platelet concentrate (APC) mixed with local autograft plus tricalcium phosphate and hydroxyapatite for posterolateral lumbar fusions. Significantly lower fusion rates were reported in the study group (74.6\%) compared to the control group (92.5\%) where APC was not added ( $\mathrm{p}=$ 0.021). However in another level II study by Jenis et al. ${ }^{175}$ autologous growth factors combined with an allograft carrier was shown to be equivalent in radiographic and clinical outcomes to autograft (89 vs. $85 \%$ fusion rates, respectively) in one or two-level instrumented lumbar interbody fusions. Radiographic follow-up at 12 months, 24 months, and longer evaluation included standing lateral flexion and extension dynamic studies. Hee et al. ${ }^{176}$ (level II) concluded after a prospective study that autologous growth factors (AGF) in one- and two-level TLIFs did not result in an overall increase in spinal fusion rates compared to autograft, although faster fusions were documented with AGF. Level III ${ }^{177}$ and level IV data ${ }^{178-180}$ are contradictory, with two studies ${ }^{18,180}$ supporting use in lumbar fusions and two others ${ }^{177,179}$ questioning efficacy in view of the inferior fusion rates obtained.

Autologous growth factors (AGF) use in cervical spine Data on the use of AGFs is limited to a double-blind randomized study ${ }^{181}$, wherein 50 patients with either degenerative disc disease or soft herniated cervical discs underwent anterior cervical fusion with allograft bone and internal fixation with or without platelet concentrates. The overall fusion rate as- sessed with plain AP and flexion extension radiographs was $84 \%$; the level of patient satisfaction, as measured by self-reported data (SF-36, VAS, and NDI) was also high. Although the effect of the platelet concentrate was positive in patients with degenerative disc disease twelve weeks after treatment, the effect did not appear to extend to other follow-up intervals or to patients with soft disc herniations, in whom a detrimental effect was observed. The authors concluded that platelet concentrate had no consistent effect in promoting early fusion in cervical disc disease associated with significant degenerative changes.

\section{Evidence Summary for Autologous Growth Factors (AGF)}

Autologous growth factor use in either lumbar or cervical spine fusions is not endorsed by the majority of the currently available level I and level II studies.

Apart from a few papers (level III and IV data) which report encouraging results, most of the available literature fails to demonstrate any significant benefit with AGF use. The added time and cost involved in obtaining growth factor concentrates intraoperatively further weaken the case for AGFs as a suitable bone graft expander.

\section{Allograft cellular bone matrix (ACBM) / Stem cell based}

\section{products}

These are stem-cell-based allografts which retain their native bone-forming cells, including mesenchymal stem cells and osteoprogenitor cells, along with bone matrix components. ACBM is a novel group of bone graft expanders and, similar to autologous bone, are believed to potentially possess all three physiologic properties involved in normal bone healing; namely osteoconduction, osteoinduction, and osteogenesis. $^{182}$

Allograft cellular bone matrix (ACBM) / Stem cell based products in lumbar spine

The clinical use of ACBM products has been reported for lumbar spine fusions in five case series (level IV) publications. ${ }^{182-186}$ Three of these reported on the 
use of a commercially available product Osteocel Plus $^{\text {TM }}$ (NuVasive Inc., San Diego, CA) whereas one study ${ }^{185}$ used enriched autologous mesenchymal stem cells (MSCs) harvested from iliac crest bone marrow in combination with porous $\beta$-TCP granules. All of these studies reported good fusion rates (ranging from $90.2 \%$ to $92.3 \%$ ) and supported the safety profile of this novel bone extender.

\section{Allograft cellular bone matrix (ACBM) / Stem cell based products in cervical spine}

Literature on use of allograft cellular bone matrix $(\mathrm{ACBM}) /$ Stem cell based products for anterior cervical discectomy and fusion procedures is very recent. In a retrospective review of a matched cohort patient population (level III), Mc Anany et al. ${ }^{187}$ evaluated 57 patients who underwent a one- or two-level instrumented ACDF procedure using interbody allograft, and Osteocel ${ }^{\mathrm{TM}}$ (NuVasive, San Diego, CA, USA). The patients were matched to a control group of 57 patients, where only interbody allograft spacer was used. At the 1-year follow-up, 50 of 57 (87.7\%) patients in the Osteocel cohort demonstrated a solid fusion compared with 54 of 57 (94.7\%) in the control group $(\mathrm{p}=0.19)$. Thus lower fusion rates were found with Osteocel group, though not statistically significant. Another commercially available ACBM that has been studied and recently quoted is Trinity Evolution $^{\mathrm{TM}}$ (Musculoskeletal Transplant Foundation, Edison, NJ, USA). Vanichkachorn ${ }^{188}$ in a prospective series (level IV) of 31 patients undergoing single level ACDF, reported a radiological fusion rate of $93.5 \%$ at 12 months follow up. Eastlack RK ${ }^{186}$ evaluated the use of Osteocel Plus ${ }^{\mathrm{TM}}$ cellular allograft for the anterior cervical discectomy and fusion of 249 levels in 182 patients (level IV). In subjects treated at a single level with a minimum of 24-month follow-up, 92\% (79/86) of levels achieved solid bridging and $95 \%$ of levels demonstrated range of motion of less than $3^{\circ}$. In combined single and 2-level procedures, $87 \%$ (157/ 180) of levels achieved solid fusion and $92 \%$ (148/ 161) exhibited range of motion less than $3^{\circ}$ at 24 months.

Evidence summary for Allograft cellular bone matrix (ACBM)/ Stem cell based products

Literature on the use of allograft cellular bone matrix/Stem cell based products is currently mostly in the form of level IV studies. More evidence on the use of these compounds for spine fusion is required to draw discrete conclusions, though limited available data show good fusion outcomes for both cervical and lumbar applications.

\section{Synthetic Peptides}

The combined use of bioactive peptides and porous implants or materials has led to a new generation of fusion extenders. ${ }^{189}$ Perhaps the most well-known, $\mathrm{P}-15^{\mathrm{TM}}$ is a 15-residue synthetic polypeptide which acts as a binding factor for osteogenic cells on a domain of type I collagen. ${ }^{190,191}$ The $\mathrm{P}-15^{\mathrm{TM}}$ peptide has been studied in a variety of animal models and is reported to enhance cell migration, induce osteoblast differentiation, and influence a pathway which results in new bone formation. ${ }^{192,193} \mathrm{P}-15^{\mathrm{TM}}$ gained FDA approval for the treatment of intrabony periodontal osseous defects due to moderate or severe periodontitis. It has been used in dental applications for over a decade and has recently been adopted for use in the spine. I-Factor $^{\mathrm{TM}}$ (Cerapedics, Inc., Westminster, $\mathrm{CO}$ ) is a proprietary composite consisting of $\mathrm{P}-15$ adsorbed to anorganic bovine bone mineral (ABM).

ABM consists of smooth, porous particles of "pure" deproteinated hydroxyapatite. ${ }^{190,192}$ This bone graft combination of ABM and P-15, also known as iFactor ${ }^{\mathrm{TM}}$, is claimed to facilitate bone formation. ${ }^{192} \mathrm{I}$ Factor $^{\mathrm{TM}}$ is indicated for use in skeletally mature patients for reconstruction of a degenerated cervical disc at one level from C3-C4 to C6-C7 following single-level discectomy for intractable radiculopathy. I-Factor ${ }^{\mathrm{TM}}$ peptide enhanced bone graft putty must be used inside an allograft bone ring and with supplemental anterior plate fixation. ${ }^{192}$

B2A is another novel synthetic peptide which is similarly purported to increase osteoblast differentiation by interacting with native BMP-2 receptors and amplifying the response to stimulus. ${ }^{194} \mathrm{~B} 2 \mathrm{~A}$ has osteoconductive and osteoinductive properties and animal model studies have demonstrated its superiority over autograft for achieving spinal fusion. ${ }^{189,195}$ BioSET $^{\circledR}$ Amplex $^{\mathrm{TM}}$ (Biosurface Engineering Technologies ${ }^{\mathrm{TM}}$, Rockville, MD) is a commercially available bone graft kit that combines B2A with bi-phasic hydroxyapatite and $B$-tricalcium phosphate granules. The ce- 
ramic granules used in Amplex ${ }^{\mathrm{TM}}$ have been FDA cleared for bone graft applications in the skeletal system.

\section{ABM/P-15 in the cervical spine}

One report (level 1) was available describing a singleblind randomized non-inferiority control trial. ${ }^{192}$ This study compared i-Factor ${ }^{\mathrm{TM}}(\mathrm{N}=165)$ to iliac crest autograft $(\mathrm{N}=154)$ for use in single-level ACDF procedures for cervical radiculopathy. At 12 months follow-up both groups demonstrated a high fusion rate $(88.97 \%$ for i-Factor and $85.82 \%$ for autograft, non-inferiority $\mathrm{p}=0.0004$ ) and equivalence with respect to the other clinical outcomes. The authors concluded that i-Factor met all FDA non-inferiority criteria and demonstrated safety and efficacy in this patient group. ${ }^{192}$

\section{ABM/P-15 in lumbar fusion}

Two articles were found describing use of $\mathrm{i}-\mathrm{Factor}^{\mathrm{rm}}$ for lumbar fusion procedures. Lauweryns et al. ${ }^{191}$ (level III) reported on a prospective clinical and radiological analysis of patients undergoing a PLIF procedure, comparing ABM/P-15 to local autograft. Two cages were placed, one on each lateral side of the interbody space, such that each patient received both the study material and autograft and therefore acted as his or her own control. ${ }^{191}$ Fusion was assessed by using CT images. At 24 months intra-cage bridging bone was observed in $95.56 \%$ of ABM/P-15 patients and $93.33 \%$ of autograft patients (no significant difference). The authors concluded that ABM/ P-15 has equal or greater efficacy at 6 and 12 months compared to autograft. ${ }^{191}$ Mobbs et al. ${ }^{196}$ (level IV) reported on a prospective analysis performed in Australia of a nonblinded cohort of patients who received $\mathrm{i}$-Factor for an ALIF. Evaluation for fusion in coronal, sagittal, and axial CT cuts was performed by two radiologists. At 24 months follow-up, $81-100 \%$ of patients who had undergone 3-, 2- or 1-level procedures exhibited fusion at all levels treated. The authors concluded that the ABM/P-15 composite demonstrated promising results for achieving fusion in patients who undergo ALIF for degenerative spinal diseases. ${ }^{196}$

Evidence summary for $A B M / P-15$

Limited available data indicate non-inferiority of
ABM/P-15 compared to autograft for single-level cervical fusion surgery. It is difficult to draw conclusions for use in the lumbar spine, although very recent level III and IV data suggest ABM/P-15 may be beneficial for lumbar fusion.

\section{B2A in the cervical spine}

No reports were found describing the clinical use of $\mathrm{B} 2 \mathrm{~A}$ in cervical spine surgery.

\section{B2A for lumbar fusion}

One article (level II) was available reporting initial results from a clinical trial comparing autograft to B2A. ${ }^{194}$ Twenty-four patients undergoing single-level TLIF were randomized to receive $150 \mathrm{mg} / \mathrm{cm}^{3}$ of B2A, $750 \mathrm{mg} / \mathrm{cm}^{3}$ granules of B2A, or ICBG. At 12-month follow-up there were non-significant differences $(p=0.08)$ in the rates of fusion, with the 750 group achieving the highest (100\%) and the 150 group the lowest (50\%). The author's concluded that a $750 \mathrm{mg} / \mathrm{cm}^{3}$ quantity of B2A appears to be superior to autograft when used for TLIF, acknowledging that no significant difference was demonstrated. ${ }^{194}$

\section{Evidence summary for B2A}

Although initial clinical reports are promising, no recommendations can be made currently based on the limited data available regarding the use of B2A in spine surgery.

\section{Discussion and conclusions}

Despite the remarkable advancements in the field of bone graft alternatives for spinal fusion, no graft substitute/expander to date has demonstrated clear superiority over autologous iliac crest graft. Autograft, although mired by issues such as donor site morbidity and limited availability, remains the gold standard for spinal fusion. The ideal bone graft substitute with equal or superior efficacy combined with a minimal complication and risk profile does not appear to exist at this time. Allograft works well as an osteoconductive scaffold with some degree of osteoinductive properties. Demineralized bone matrix is associated with variable outcomes and is dependent upon the formulation used and differences in factors such as product batch. Ceramics appear to be a promising group of bone graft extenders, especially when com- 
bined with bone marrow aspirates. The most published and extensively studied group of rhBMPs likely came closest to dethroning iliac crest autograft, when promising early reports emerged over a decade ago. However their complication profile, which was beyond the scope of discussion of this review, as well recent studies re-evaluating the risks/benefits with BMP use, require physicians to reconsider their routine application in spinal fusion procedures. Autologous growth factors and platelet gels have failed to demonstrate any advantage in terms of fusion efficacy. Lastly, data on stem cell based products and the synthetic peptides is currently very limited, having only recently popped up on the horizon. More better quality studies are required comparing these substitutes and extenders not just with autografts, but also with each other. Nevertheless, with such a plethora of available options, and with such diversity in the data on their application under different scenarios and in different combinations, it becomes necessary for spine surgeons to scrutinize all options carefully before adopting them in clinical practice.

\section{Acknowledgements}

The authors wish to thank Robin Hashimoto, PhD, and Joseph R. Dettori, PhD, MPH for their assistance in the preparation of this manuscript.

\section{References}

1. Wright JG, Swiontkowski MF, Heckman JD. Introducing levels of evidence to the journal. J Bone Joint Surg Am. 2003;85-A(1):1-3.

2. Stevenson S, Emery SE, Goldberg VM. Factors affecting bone graft incorporation. Clin Orthop Relat Res. 1996;(324):66-74.

3. Hamer AJ, Strachan JR, Black MM, Ibbotson CJ, Stockley I, Elson RA. Biochemical properties of cortical allograft bone using a new method of bone strength measurement. A comparison of fresh, freshfrozen and irradiated bone. J Bone Joint Surg Br. 1996;78(3):363-368.

4. Graham RS, Samsell BJ, Proffer A, et al. Evaluation of glycerol-preserved bone allografts in cervical spine fusion: a prospective, randomized controlled trial. J Neurosurg Spine. 2015;22(1):1-10. doi:10.3171/
2014.9.SPINE131005.

5. Godzik J, Ravindra VM, Ray WZ, Schmidt MH, Bisson EF, Dailey AT. Comparison of structural allograft and traditional autograft technique in occipitocervical fusion: radiological and clinical outcomes from a single institution. J Neurosurg Spine.

2015;23(2):144-152. doi:10.3171/

2014.12.SPINE14535.

6. Hillard VH, Fassett DR, Finn MA, Apfelbaum

RI. Use of allograft bone for posterior C1-2 fusion. $J$ Neurosurg Spine. 2009;11(4):396-401. doi:10.3171/ 2009.5.SPINE08662.

7. Yue W-M, Brodner W, Highland TR. Long-term results after anterior cervical discectomy and fusion with allograft and plating: a 5- to 11-year radiologic and clinical follow-up study. Spine (Phila Pa 1976). 2005;30(19):2138-2144.

8. Suchomel P, Barsa P, Buchvald P, Svobodnik A, Vanickova E. Autologous versus allogenic bone grafts in instrumented anterior cervical discectomy and fusion: a prospective study with respect to bone union pattern. Eur Spine J. 2004;13(6):510-515. doi:10.1007/s00586-003-0667-z.

9. Samartzis D, Shen FH, Matthews DK, Yoon ST, Goldberg EJ, An HS. Comparison of allograft to autograft in multilevel anterior cervical discectomy and fusion with rigid plate fixation. Spine J. 3(6):451-459. 10. Kaiser MG, Haid RW, Subach BR, Barnes B, Rodts GE. Anterior cervical plating enhances arthrodesis after discectomy and fusion with cortical allograft. Neurosurgery. 2002;50(2):229-236; discussion 236-238.

11. McKoy BE, Wingate JK, Poletti SC, Johnson DR, Stanley MD, Glaser JA. Fibular allograft after anterior cervical corpectomy: long term follow-up. Iowa Orthop J. 2002;22:42-46.

12. Martin GJ, Haid RW, MacMillan M, Rodts GE, Berkman R. Anterior cervical discectomy with freeze-dried fibula allograft. Overview of 317 cases and literature review. Spine (Phila Pa 1976). 1999;24(9):852-858; discussion 858-859.

13. Bishop RC, Moore KA, Hadley MN. Anterior cervical interbody fusion using autogeneic and allogeneic bone graft substrate: a prospective comparative analysis. J Neurosurg. 1996;85(2):206-210. doi:10.3171/jns.1996.85.2.0206.

14. Grossman W, Peppelman WC, Baum JA, Kraus 
DR. The use of freeze-dried fibular allograft in anterior cervical fusion. Spine (Phila Pa 1976). 1992;17(5):565-569.

15. Fernyhough JC, White JI, LaRocca H. Fusion rates in multilevel cervical spondylosis comparing allograft fibula with autograft fibula in 126 patients. Spine (Phila Pa 1976). 1991;16(10 Suppl):S561-S564. 16. Zdeblick TA, Ducker TB. The use of freezedried allograft bone for anterior cervical fusions. Spine (Phila Pa 1976). 1991;16(7):726-729.

17. Brown MD, Malinin TI, Davis PB. A roentgenographic evaluation of frozen allografts versus autografts in anterior cervical spine fusions. Clin Orthop Relat Res. 1976;(119):231-236.

18. Hart R, Komzák M, Okál F, Náhlík D, Jajtner P, Puskeiler M. Allograft alone versus allograft with bone marrow concentrate for the healing of the instrumented posterolateral lumbar fusion. Spine $J$. 2014;14(7):1318-1324. doi:10.1016/

j.spinee.2013.12.014.

19. Johnson RG. Bone marrow concentrate with allograft equivalent to autograft in lumbar fusions. Spine (Phila Pa 1976). 2014;39(9):695-700. doi:10.1097/BRS.0000000000000254.

20. Urrutia J, Molina M. Fresh-frozen femoral head allograft as lumbar interbody graft material allows high fusion rate without subsidence. Orthop Traumatol Surg Res. 2013;99(4):413-418. doi:10.1016/ j.otsr.2013.03.010.

21. Putzier M, Strube P, Funk JF, et al. Allogenic versus autologous cancellous bone in lumbar segmental spondylodesis: a randomized prospective study. Eur Spine J. 2009;18(5):687-695. doi:10.1007/ s00586-008-0875-7.

22. Thalgott JS, Fogarty ME, Giuffre JM, Christenson SD, Epstein AK, Aprill C. A prospective, randomized, blinded, single-site study to evaluate the clinical and radiographic differences between frozen and freeze-dried allograft when used as part of a circumferential anterior lumbar interbody fusion procedure. Spine (Phila Pa 1976). 2009;34(12):1251-1256. doi:10.1097/BRS.0b013e3181a005d7.

23. Sarwat AM, O'Brien JP, Renton P, Sutcliffe JC. The use of allograft (and avoidance of autograft) in anterior lumbar interbody fusion: a critical analysis. Eur Spine J. 2001;10(3):237-241.

24. Bendo JA, Spivak JM, Neuwirth MG, Chung P.
Use of the anterior interbody fresh-frozen femoral head allograft in circumferential lumbar fusions. $J$ Spinal Disord. 2000;13(2):144-149.

25. An HS, Lynch K, Toth J. Prospective comparison of autograft vs. allograft for adult posterolateral lumbar spine fusion: differences among freeze-dried, frozen, and mixed grafts. J Spinal Disord. 1995;8(2):131-135.

26. Jorgenson SS, Lowe TG, France J, Sabin J. A prospective analysis of autograft versus allograft in posterolateral lumbar fusion in the same patient. A minimum of 1-year follow-up in 144 patients. Spine (Phila Pa 1976). 1994;19(18):2048-2053.

27. Kumar A, Kozak JA, Doherty BJ, Dickson JH. Interspace distraction and graft subsidence after anterior lumbar fusion with femoral strut allograft. Spine (Phila Pa 1976). 1993;18(16):2393-2400.

28. Wimmer C, Krismer M, Gluch H, Ogon M, Stöckl B. Autogenic versus allogenic bone grafts in anterior lumbar interbody fusion. Clin Orthop Relat Res. 1999;(360):122-126.

29. Ajiboye RM, Hamamoto JT, Eckardt MA, Wang JC. Clinical and radiographic outcomes of concentrated bone marrow aspirate with allograft and demineralized bone matrix for posterolateral and interbody lumbar fusion in elderly patients. Eur Spine J. 2015;24(11):2567-2572. doi:10.1007/ s00586-015-4117-5.

30. Dodd CA, Fergusson CM, Freedman L, Houghton GR, Thomas D. Allograft versus autograft bone in scoliosis surgery. J Bone Joint Surg Br. 1988;70(3):431-434.

31. Aurori BF, Weierman RJ, Lowell HA, Nadel CI, Parsons JR. Pseudarthrosis after spinal fusion for scoliosis. A comparison of autogeneic and allogeneic bone grafts. Clin Orthop Relat Res.

1985;(199):153-158.

32. Jones KC, Andrish J, Kuivila T, Gurd A. Radiographic outcomes using freeze-dried cancellous allograft bone for posterior spinal fusion in pediatric idiopathic scoliosis. J Pediatr Orthop. 22(3):285-289. 33. Yazici $M$, Asher MA. Freeze-dried allograft for posterior spinal fusion in patients with neuromuscular spinal deformities. Spine (Phila Pa 1976). 1997;22(13):1467-1471.

34. Bridwell KH, O'Brien MF, Lenke LG, Baldus $\mathrm{C}$, Blanke K. Posterior spinal fusion supplemented 
with only allograft bone in paralytic scoliosis. Does it work? Spine (Phila Pa 1976). 1994;19(23):2658-2666. 35. Murphy RF, Glotzbecker MP, Hresko MT, Hedequist D. Allograft Bone Use in Pediatric Subaxial Cervical Spine Fusions. J Pediatr Orthop. November 2015. doi:10.1097/BPO.0000000000000691. 36. Demirkıran HG, Akel I, Yılmaz G, Ayvaz M, Alanay A, Yazıcı M. Long-segment posterior instrumentation and fusion with freeze-dried allograft in congenital scoliosis. Acta Orthop Traumatol Turc. 2012;46(4):275-280.

37. Finkelstein JA, Chapman JR, Mirza S. Anterior cortical allograft in thoracolumbar fractures. J Spinal Disord. 1999;12(5):424-429.

38. Singh K, DeWald CJ, Hammerberg KW, DeWald RL. Long structural allografts in the treatment of anterior spinal column defects. Clin Orthop Relat Res. 2002;(394):121-129.

39. Govender S, Parbhoo AH. Support of the anterior column with allografts in tuberculosis of the spine. J Bone Joint Surg Br. 1999;81(1):106-109. 40. Govender S. The outcome of allografts and anterior instrumentation in spinal tuberculosis. Clin Orthop Relat Res. 2002;(398):60-66.

41. Govender S, Kumar KPS. Cortical allografts in spinal tuberculosis. Int Orthop. 2003;27(4):244-248. doi:10.1007/s00264-003-0446-9.

42. Schuster JM, Avellino AM, Mann FA, et al. Use of structural allografts in spinal osteomyelitis: a review of 47 cases. J Neurosurg. 2000;93(1 Suppl):8-14. 43. An HS, Simpson JM, Glover JM, Stephany J. Comparison between allograft plus demineralized bone matrix versus autograft in anterior cervical fusion. A prospective multicenter study. Spine (Phila Pa 1976). 1995;20(20):2211-2216.

44. Moon HJ, Kim JH, Kim J-H, Kwon T-H, Chung H-S, Park Y-K. The effects of anterior cervical discectomy and fusion with stand-alone cages at two contiguous levels on cervical alignment and outcomes. Acta Neurochir (Wien). 2011;153(3):559-565. doi:10.1007/s00701-010-0879-z.

45. Topuz K, Colak A, Kaya S, et al. Two-level contiguous cervical disc disease treated with peek cages packed with demineralized bone matrix: results of 3-year follow-up. Eur Spine J. 2009;18(2):238-243. doi:10.1007/s00586-008-0869-5.

46. Park H-W, Lee J-K, Moon S-J, Seo S-K, Lee J-
$\mathrm{H}, \mathrm{Kim} \mathrm{S}-\mathrm{H}$. The efficacy of the synthetic interbody cage and Grafton for anterior cervical fusion. Spine (Phila Pa 1976). 2009;34(17):E591-E595. doi:10.1097/BRS.0b013e3181ab8b9a.

47. Demircan MN, Kutlay AM, Colak A, et al. Multilevel cervical fusion without plates, screws or autogenous iliac crest bone graft. J Clin Neurosii. 2007;14(8):723-728. doi:10.1016/j.jocn.2006.02.026. 48. Kang J, An H, Hilibrand A, Yoon ST, Kavanagh E, Boden S. Grafton and local bone have comparable outcomes to iliac crest bone in instrumented singlelevel lumbar fusions. Spine (Phila Pa 1976).

2012;37(12):1083-1091. doi:10.1097/

BRS.0b013e31823ed817.

49. Hoffmann MF, Jones CB, Sietsema DL. Adjuncts in posterior lumbar spine fusion: comparison of complications and efficacy. Arch Orthop Trauma Surg. 2012;132(8):1105-1110. doi:10.1007/ s00402-012-1529-0.

50. Schizas C, Triantafyllopoulos D, Kosmopoulos V, Tzinieris N, Stafylas K. Posterolateral lumbar spine fusion using a novel demineralized bone matrix: a controlled case pilot study. Arch Orthop Trauma Surg. 2008;128(6):621-625. doi:10.1007/ s00402-007-0495-4.

51. Epstein NE. Fusion rates and SF-36 outcomes after multilevel laminectomy and noninstrumented lumbar fusions in a predominantly geriatric population. J Spinal Disord Tech. 2008;21(3):159-164. doi:10.1097/BSD.0b013e318074ddaa.

52. Epstein NE, Epstein JA. SF-36 outcomes and fusion rates after multilevel laminectomies and 1 and 2-level instrumented posterolateral fusions using lamina autograft and demineralized bone matrix. $J$ Spinal Disord Tech. 2007;20(2):139-145. doi:10.1097/ 01.bsd.0000211261.36120.3e.

53. Vaccaro AR, Stubbs HA, Block JE. Demineralized bone matrix composite grafting for posterolateral spinal fusion. Orthopedics. 2007;30(7):567-570.

54. Cammisa FP, Lowery G, Garfin SR, et al. Twoyear fusion rate equivalency between Grafton DBM gel and autograft in posterolateral spine fusion: a prospective controlled trial employing a side-by-side comparison in the same patient. Spine (Phila Pa 1976). 2004;29(6):660-666.

55. Girardi FP, Cammisa FP. The effect of bone graft extenders to enhance the performance of iliac 
crest bone grafts in instrumented lumbar spine fusion. Orthopedics. 2003;26(5 Suppl):s545-s548. 56. Sassard WR, Eidman DK, Gray PM, et al. Augmenting local bone with Grafton demineralized bone matrix for posterolateral lumbar spine fusion: avoiding second site autologous bone harvest. Orthopedics. 2000;23(10):1059-1064; discussion 1064-1065.

57. Thalgott JS, Giuffre JM, Klezl Z, Timlin M. Anterior lumbar interbody fusion with titanium mesh cages, coralline hydroxyapatite, and demineralized bone matrix as part of a circumferential fusion. Spine J. 2(1):63-69.

58. Thalgott JS, Giuffre JM, Fritts K, Timlin M, Klezl Z. Instrumented posterolateral lumbar fusion using coralline hydroxyapatite with or without demineralized bone matrix, as an adjunct to autologous bone. Spine J. 1(2):131-137.

59. Fu T-S, Wang I-C, Lu M-L, Hsieh M-K, Chen $\mathrm{L}-\mathrm{H}, \mathrm{Chen} \mathrm{W}-\mathrm{J}$. The fusion rate of demineralized bone matrix compared with autogenous iliac bone graft for long multi-segment posterolateral spinal fusion. BMC Musculoskelet Disord. 2016;17(1):3. doi:10.1186/s12891-015-0861-2.

60. Baumann F, Krutsch W, Pfeifer C, Neumann C, Nerlich M, Loibl M. Posterolateral fusion in acute traumatic thoracolumbar fractures: a comparison of demineralized bone matrix and autologous bone graft. Acta Chir Orthop Traumatol Cech. 2015;82(2):119-125.

61. Weinzapfel B, Son-Hing JP, Armstrong DG, Blakemore LC, Poe-Kochert C, Thompson GH. Fusion rates after thoracoscopic release and bone graft substitutes in idiopathic scoliosis. Spine (Phila Pa 1976). 2008;33(10):1079-1083. doi:10.1097/

BRS.0b013e31816f69b3.

62. Price CT, Connolly JF, Carantzas AC, Ilyas I. Comparison of bone grafts for posterior spinal fusion in adolescent idiopathic scoliosis. Spine (Phila Pa 1976). 2003;28(8):793-798.

63. Dai L-Y, Jiang L-S. Single-level instrumented posterolateral fusion of lumbar spine with betatricalcium phosphate versus autograft: a prospective, randomized study with 3-year follow-up. Spine (Phila Pa 1976). 2008;33(12):1299-1304. doi:10.1097/ BRS.0b013e3181732a8e.

64. Yamada T, Yoshii T, Sotome S, et al. Hybrid grafting using bone marrow aspirate combined with porous $\beta$-tricalcium phosphate and trephine bone for lumbar posterolateral spinal fusion: a prospective, comparative study versus local bone grafting. Spine (Phila Pa 1976). 2012;37(3):E174-E179. doi:10.1097/ BRS.0b013e3182269d64.

65. Kong S, Park JH, Roh SW. A prospective comparative study of radiological outcomes after instrumented posterolateral fusion mass using autologous local bone or a mixture of beta-tcp and autologous local bone in the same patient. Acta Neurochir (Wien). 2013;155(5):765-770. doi:10.1007/s00701-013-1669-1. 66. Thaler M, Lechner R, Gstöttner M, Kobel C, Bach C. The use of beta-tricalcium phosphate and bone marrow aspirate as a bone graft substitute in posterior lumbar interbody fusion. Eur Spine $J$. 2013;22(5):1173-1182. doi:10.1007/ s00586-012-2541-3.

67. Epstein NE. Beta tricalcium phosphate: observation of use in 100 posterolateral lumbar instrumented fusions. Spine J. 2009;9(8):630-638. doi:10.1016/j.spinee.2009.04.007.

68. Epstein NE. A preliminary study of the efficacy of Beta Tricalcium Phosphate as a bone expander for instrumented posterolateral lumbar fusions. J Spinal Disord Tech. 2006;19(6):424-429.

69. Park JH, Choi CG, Jeon SR, Rhim SC, Kim CJ, Roh SW. Radiographic Analysis of Instrumented Posterolateral Fusion Mass Using Mixture of Local Autologous Bone and b-TCP (PolyBone ${ }^{\circledR}$ ) in a Lumbar Spinal Fusion Surgery. J Korean Neurosurg Soc. 2011;49(5):267-272. doi:10.3340/jkns.2011.49.5.267. 70. Kanter AS, Gandhoke GS, Welch WC, Arnold PM, Cheng JS, Okonkwo DO. A prospective, multicenter clinical and radiographic outcomes evaluation of ChronOS strip for lumbar spine fusion. J Clin Neurosci. 2016;25:36-40. doi:10.1016/ j.jocn.2015.08.012.

71. Epstein NE. Preliminary study showing safety/ efficacy of nanoss bioactive versus vitoss as bone graft expanders for lumbar noninstrumented fusions. Surg Neurol Int. 2015;6(Suppl 10):S318-S322. doi:10.4103/2152-7806.159380.

72. Dai L-Y, Jiang L-S. Anterior cervical fusion with interbody cage containing beta-tricalcium phosphate augmented with plate fixation: a prospective randomized study with 2-year follow-up. Eur Spine J. 2008;17(5):698-705. doi:10.1007/ 
s00586-008-0643-8.

73. Sugawara T, Itoh Y, Hirano Y, Higashiyama N, Mizoi K. $\beta$-Tricalcium phosphate promotes bony fusion after anterior cervical discectomy and fusion using titanium cages. Spine (Phila Pa 1976).

2011;36(23):E1509-E1514. doi:10.1097/

BRS.0b013e31820e60d9.

74. Ahn JS, Lee JK, Kim JH. Comparative study of clinical outcomes of anterior cervical discectomy and fusion using autobone graft or cage with bone substitute. Asian Spine J. 2011;5(3):169-175. doi:10.4184/ asj.2011.5.3.169.

75. Epstein NE. Efficacy of posterior cervical fusions utilizing an artificial bone graft expander, beta tricalcium phosphate. Surg Neurol Int. 2011;2:15. doi:10.4103/2152-7806.76458.

76. Epstein NE. Preliminary documentation of the comparable efficacy of vitoss versus NanOss bioactive as bone graft expanders for posterior cervical fusion. Surg Neurol Int. 2015;6(Suppl 4):S164-S171. doi:10.4103/2152-7806.156559.

77. Lerner T, Bullmann V, Schulte TL, Schneider $M$, Liljenqvist U. A level-1 pilot study to evaluate of ultraporous beta-tricalcium phosphate as a graft extender in the posterior correction of adolescent idiopathic scoliosis. Eur Spine J. 2009;18(2):170-179. doi:10.1007/s00586-008-0844-1.

78. Delécrin J, Takahashi S, Gouin F, Passuti N. A synthetic porous ceramic as a bone graft substitute in the surgical management of scoliosis: a prospective, randomized study. Spine (Phila Pa 1976).

2000;25(5):563-569.

79. Muschik M, Ludwig R, Halbhübner S, Bursche $\mathrm{K}$, Stoll T. Beta-tricalcium phosphate as a bone substitute for dorsal spinal fusion in adolescent idiopathic scoliosis: preliminary results of a prospective clinical study. Eur Spine J. 2001;10 Suppl 2:S178-S184. doi:10.1007/s005860100271.

80. Roberts TT, Rosenbaum AJ. Bone grafts, bone substitutes and orthobiologics: the bridge between basic science and clinical advancements in fracture healing. Organogenesis. 8(4):114-124. doi:10.4161/ org.23306.

81. Jarcho M. Calcium phosphate ceramics as hard tissue prosthetics. Clin Orthop Relat Res. 1981;(157):259-278.

82. Korovessis P, Koureas G, Zacharatos S, Papazi- sis Z, Lambiris E. Correlative radiological, selfassessment and clinical analysis of evolution in instrumented dorsal and lateral fusion for degenerative lumbar spine disease. Autograft versus coralline hydroxyapatite. Eur Spine J. 2005;14(7):630-638. doi:10.1007/s00586-004-0855-5.

83. Hsu C-J, Chou W-Y, Teng H-P, Chang W-N, Chou Y-J. Coralline hydroxyapatite and laminectomy-derived bone as adjuvant graft material for lumbar posterolateral fusion. J Neurosurg Spine. 2005;3(4):271-275. doi:10.3171/spi.2005.3.4.0271. 84. Kim H, Lee C-K, Yeom J-S, Lee J-H, Lee K-H, Chang B-S. The efficacy of porous hydroxyapatite bone chip as an extender of local bone graft in posterior lumbar interbody fusion. Eur Spine J.

2012;21(7):1324-1330. doi:10.1007/

s00586-011-2092-z.

85. Thalgott JS, Klezl Z, Timlin M, Giuffre JM.

Anterior lumbar interbody fusion with processed sea coral (coralline hydroxyapatite) as part of a circumferential fusion. Spine (Phila Pa 1976).

2002;27(24):E518-E525; discussion E526-E527. doi:10.1097/01.BRS.0000035730.11228.AD.

86. Robbins S, Lauryssen C, Songer MN. Use of Nanocrystalline Hydroxyapatite With Autologous BMA and Local Bone in the Lumbar Spine: A Retrospective CT Analysis of Posterolateral Fusion Results. J Spinal Disord Tech. February 2014. doi:10.1097/BSD.0000000000000091. 87. McConnell JR, Freeman BJC, Debnath UK, Grevitt MP, Prince HG, Webb JK. A prospective randomized comparison of coralline hydroxyapatite with autograft in cervical interbody fusion. Spine (Phila Pa 1976). 2003;28(4):317-323. doi:10.1097/ 01.BRS.0000048503.51956.E1.

88. Thalgott JS, Fritts K, Giuffre JM, Timlin M. Anterior interbody fusion of the cervical spine with coralline hydroxyapatite. Spine (Phila Pa 1976). 1999;24(13):1295-1299.

89. Suetsuna F, Yokoyama T, Kenuka E, Harata S. Anterior cervical fusion using porous hydroxyapatite ceramics for cervical disc herniation. a two-year follow-up. Spine J. 1(5):348-357.

90. Yoshii T, Yuasa M, Sotome S, et al. Porous/ dense composite hydroxyapatite for anterior cervical discectomy and fusion. Spine (Phila Pa 1976). 2013;38(10):833-840. doi:10.1097/ 
BRS.0b013e3182801390.

91. Yang X, Liu L, Song Y, Kong Q, Zeng J, Tu C.

Outcome of single level anterior cervical discectomy and fusion using nano-hydroxyapatite/polyamide-66 cage. Indian J Orthop. 2014;48(2):152-157.

doi:10.4103/0019-5413.128753.

92. Mashoof AA, Siddiqui SA, Otero M, Tucci JJ.

Supplementation of autogenous bone graft with

coralline hydroxyapatite in posterior spine fusion for idiopathic adolescent scoliosis. Orthopedics.

2002;25(10):1073-1076.

93. Wang Z, Sakakibara T, Sudo A, Kasai Y. Porosity of $\beta$-tricalcium phosphate affects the results of lumbar posterolateral fusion. J Spinal Disord Tech. 2013;26(2):E40-E45. doi:10.1097/

BSD.0b013e31823db5e6.

94. Niu C-C, Tsai T-T, Fu T-S, Lai P-L, Chen L-H, Chen W-J. A comparison of posterolateral lumbar fusion comparing autograft, autogenous laminectomy bone with bone marrow aspirate, and calcium sulphate with bone marrow aspirate: a prospective randomized study. Spine (Phila Pa 1976).

2009;34(25):2715-2719. doi:10.1097/

BRS.0b013e3181b47232.

95. Alexander DI, Manson NA, Mitchell MJ. Efficacy of calcium sulfate plus decompression bone in lumbar and lumbosacral spinal fusion: preliminary results in 40 patients. Can J Surg.

2001;44(4):262-266.

96. Chen W-J, Tsai T-T, Chen L-H, et al. The fusion rate of calcium sulfate with local autograft bone compared with autologous iliac bone graft for instrumented short-segment spinal fusion. Spine (Phila Pa 1976). 2005;30(20):2293-2297.

97. Chang C-H, Lin M-Z, Chen Y-J, Hsu H-C, Chen H-T. Local autogenous bone mixed with bone expander: an optimal option of bone graft in singlesegment posterolateral lumbar fusion. Surg Neurol. 2008;70 Suppl 1:S1:47-49; discussion S1:49. doi:10.1016/j.surneu.2008.05.022.

98. Guth K, Buckland T, Hing KA. Silicon Dissolution from Microporous Silicon Substituted Hydroxyapatite and its Effect on Osteoblast Behaviour. Key Eng Mater. 2006;309-311:117-120.

99. Wenisch S, Stahl J-P, Horas U, et al. In vivo mechanisms of hydroxyapatite ceramic degradation by osteoclasts: fine structural microscopy. J Biomed
Mater Res A. 2003;67(3):713-718. doi:10.1002/ jbm.a.10091.

100. Nandyala S V, Marquez-Lara A, Singh K. A Prospective, Randomized, Controlled Trial of Silicate Substituted Calcium Phosphate Versus rhBMP-2 in a Minimally Invasive Transforaminal Lumbar Interbody Fusion. Spine (Phila Pa 1976). November 2013. doi:10.1097/BRS.0000000000000106. 101. Pimenta L, Marchi L, Oliveira L, Coutinho E, Amaral R. A prospective, randomized, controlled trial comparing radiographic and clinical outcomes between stand-alone lateral interbody lumbar fusion with either silicate calcium phosphate or rh-BMP2. $J$ Neurol Surg A Cent Eur Neurosurg. 2013;74(6):343-350. doi:10.1055/s-0032-1333420. 102. Jenis LG, Banco RJ. Efficacy of silicatesubstituted calcium phosphate ceramic in posterolateral instrumented lumbar fusion. Spine (Phila $\mathrm{Pa}$ 1976). 2010;35(20):E1058-E1063. doi:10.1097/ BRS.0b013e3181df196f.

103. Nagineni V V, James AR, Alimi M, et al. Silicate-substituted calcium phosphate ceramic bone graft replacement for spinal fusion procedures. Spine (Phila Pa 1976). 2012;37(20):E1264-E1272. doi:10.1097/BRS.0b013e318265e22e.

104. Harshavardhana NS, Noordeen MHH. Surgical results with the use of Silicated Calcium Phosphate ( $\mathrm{SiCaP}$ ) as bone graft substitute in Posterior Spinal Fusion (PSF) for Adolescent Idiopathic Scoliosis (AIS). Scoliosis. 2015;10:27. doi:10.1186/ s13013-015-0051-x.

105. Lerner T, Liljenqvist U. Silicate-substituted calcium phosphate as a bone graft substitute in surgery for adolescent idiopathic scoliosis. Eur Spine J. 2013;22 Suppl 2:S185-S194. doi:10.1007/ s00586-012-2485-7.

106. Lee JH, Lee DH, Ryu HS, Chang B-S, Hong KS, Lee CK. Porous Beta-Calcium Pyrophosphate as a Bone Graft Substitute in a Canine Bone Defect Model. Key Eng Mater. 2002;240-242:399-402. 107. Lee JH, Chang B-S, Jeung U-O, Park K-W, Kim M-S, Lee C-K. The first clinical trial of betacalcium pyrophosphate as a novel bone graft extender in instrumented posterolateral lumbar fusion. Clin Orthop Surg. 2011;3(3):238-244. doi:10.4055/ cios.2011.3.3.238.

108. Rihn JA, Kirkpatrick K, Albert TJ. Graft op- 
tions in posterolateral and posterior interbody lumbar fusion. Spine (Phila Pa 1976).

2010;35(17):1629-1639. doi:10.1097/

BRS.0b013e3181d25803.

109. Michielsen J, Sys J, Rigaux A, Bertrand C. The effect of recombinant human bone morphogenetic protein-2 in single-level posterior lumbar interbody arthrodesis. J Bone Joint Surg Am. 2013;95(10):873-880. doi:10.2106/JBJS.L.00137. 110. Hurlbert RJ, Alexander D, Bailey $S$, et al. rhBMP-2 for posterolateral instrumented lumbar fusion: a multicenter prospective randomized controlled trial. Spine (Phila Pa 1976).

2013;38(25):2139-2148. doi:10.1097/

BRS.0000000000000007.

111. Dimar JR 2nd, Glassman SD, Burkus JK, Pryor PW, Hardacker JW CL. Clinical and radiographic analysis of an optimized rhBMP-2 formulation as an autograft replacement in posterolateral lumbar spine arthrodesis. J Bone Jt Surg Am.

http://www.ncbi.nlm.nih.gov/pubmed/19487515. Accessed February 6, 2014.

112. Glassman SD, Carreon LY, Djurasovic M, et al. RhBMP-2 versus iliac crest bone graft for lumbar spine fusion: a randomized, controlled trial in patients over sixty years of age. Spine (Phila Pa 1976). 2008;33(26):2843-2849. doi:10.1097/

BRS.0b013e318190705d.

113. Dimar JR, Glassman SD, Burkus KJ, Carreon LY. Clinical outcomes and fusion success at 2 years of single-level instrumented posterolateral fusions with recombinant human bone morphogenetic protein-2/compression resistant matrix versus iliac crest bone graft. Spine (Phila Pa 1976).

2006;31(22):2534-2539; discussion 2540. doi:10.1097/01.brs.0000240715.78657.81. 114. Burkus JK, Sandhu HS, Gornet MF, Longley MC. Use of rhBMP-2 in combination with structural cortical allografts: clinical and radiographic outcomes in anterior lumbar spinal surgery. J Bone Joint Surg Am. 2005;87(6):1205-1212. doi:10.2106/JBJS.D.02532.

115. Boden SD, Kang J, Sandhu H, Heller JG. Use of recombinant human bone morphogenetic protein-2 to achieve posterolateral lumbar spine fusion in humans: a prospective, randomized clinical pilot trial: 2002 Volvo Award in clinical studies. Spine
(Phila Pa 1976). 2002;27(23):2662-2673. doi:10.1097/01.BRS.0000035320.82533.06. 116. Dawson E, Bae HW, Burkus JK, Stambough JL, Glassman SD. Recombinant human bone morphogenetic protein-2 on an absorbable collagen sponge with an osteoconductive bulking agent in posterolateral arthrodesis with instrumentation. A prospective randomized trial. J Bone Joint Surg Am. 2009;91(7):1604-1613. doi:10.2106/JBJS.G.01157. 117. Katayama $Y$, Matsuyama $Y$, Yoshihara H, et al. Clinical and radiographic outcomes of posterolateral lumbar spine fusion in humans using recombinant human bone morphogenetic protein-2: an average five-year follow-up study. Int Orthop. 2009;33(4):1061-1067. doi:10.1007/ s00264-008-0600-5.

118. Slosar PJ, Josey R, Reynolds J. Accelerating lumbar fusions by combining rhBMP-2 with allograft bone: a prospective analysis of interbody fusion rates and clinical outcomes. Spine J. 7(3):301-307. doi:10.1016/j.spinee.2006.10.015.

119. Singh K, Smucker JD, Gill S, Boden SD. Use of recombinant human bone morphogenetic protein- 2 as an adjunct in posterolateral lumbar spine fusion: a prospective CT-scan analysis at one and two years. J Spinal Disord Tech. 2006;19(6):416-423. 120. Haid RW, Branch CL, Alexander JT, Burkus JK. Posterior lumbar interbody fusion using recombinant human bone morphogenetic protein type 2 with cylindrical interbody cages. Spine J. 4(5):527-538; discussion 538-539. doi:10.1016/

j.spinee.2004.03.025.

121. Burkus JK, Dorchak JD, Sanders DL. Radiographic assessment of interbody fusion using recombinant human bone morphogenetic protein type 2. Spine (Phila Pa 1976). 2003;28(4):372-377. doi:10.1097/01.BRS.0000048469.45035.B9. 122. Burkus JK, Gornet MF, Dickman CA, Zdeblick TA. Anterior lumbar interbody fusion using rhBMP-2 with tapered interbody cages. J Spinal Disord Tech. 2002;15(5):337-349.

123. Boden SD, Zdeblick TA, Sandhu HS, Heim $\mathrm{SE}$. The use of rhBMP-2 in interbody fusion cages. Definitive evidence of osteoinduction in humans: a preliminary report. Spine (Phila Pa 1976). 2000;25(3):376-381.

124. Adams CL, Ogden K, Robertson IK, Broad- 
hurst S, Edis D. Effectiveness and safety of recombinant human bone morphogenetic protein-2 versus local bone graft in primary lumbar interbody fusions.

Spine (Phila Pa 1976). 2014;39(2):164-171.

doi:10.1097/BRS.0000000000000089.

125. Crandall DG, Revella J, Patterson J, Huish E, Chang M, McLemore R. Transforaminal lumbar interbody fusion with rhBMP-2 in spinal deformity, spondylolisthesis, and degenerative disease--part 1: Large series diagnosis related outcomes and complications with 2- to 9-year follow-up. Spine (Phila Pa 1976). 2013;38(13):1128-1136. doi:10.1097/

BRS.0b013e31828864e6.

126. Crandall DG, Revella J, Patterson J, Huish E, Chang M, McLemore R. Transforaminal lumbar interbody fusion with rhBMP-2 in spinal deformity, spondylolisthesis, and degenerative disease--part 2: BMP dosage-related complications and long-term outcomes in 509 patients. Spine (Phila Pa 1976). 2013;38(13):1137-1145. doi:10.1097/

BRS.0b013e3182880298.

127. Gerszten PC, Tobler WD, Nasca RJ. Retrospective analysis of L5-S1 axial lumbar interbody fusion (AxiaLIF): a comparison with and without the use of recombinant human bone morphogenetic protein-2. Spine J. 2011;11(11):1027-1032. doi:10.1016/ j.spinee.2011.10.006.

128. Lee K-B, Taghavi CE, Hsu MS, et al. The efficacy of rhBMP-2 versus autograft for posterolateral lumbar spine fusion in elderly patients. Eur Spine J. 2010;19(6):924-930. doi:10.1007/

s00586-009-1248-6.

129. Glassman SD. The efficacy of rhBMP-2 for posterolateral lumbar fusion in smokers. Spine (Phila Pa 1976). 2007;32(15):1693-1698. doi:10.1097/ BRS.0b013e318074c366.

130. Glassman SD, Carreon L, Djurasovic M, et al. Posterolateral lumbar spine fusion with INFUSE bone graft. Spine J. 7(1):44-49. doi:10.1016/ j.spinee.2006.06.381.

131. Mummaneni P V, Pan J, Haid RW, Rodts GE. Contribution of recombinant human bone morphogenetic protein-2 to the rapid creation of interbody fusion when used in transforaminal lumbar interbody fusion: a preliminary report. Invited submission from the Joint Section Meeting on Disorders of the Spine. JNeurosurg Spine. 2004;1(1):19-23. doi:10.3171/ spi.2004.1.1.0019.

132. Park DK, Kim SS, Thakur N, Boden SD. Use of Recombinant Human Bone Morphogenetic Protein-2 With Local Bone Graft Instead of Iliac Crest Bone Graft in Posterolateral Lumbar Spine Arthrodesis. Spine (Phila Pa 1976). March 2013. doi:10.1097/BRS.0b013e31828fd23c.

133. Geibel PT, Boyd DL, Slabisak V. The use of recombinant human bone morphogenic protein in posterior interbody fusions of the lumbar spine: a clinical series. J Spinal Disord Tech. 2009;22(5):315-320. doi:10.1097/BSD.0b013e31817d8161.

134. Rihn JA, Makda J, Hong J, et al. The use of RhBMP-2 in single-level transforaminal lumbar interbody fusion: a clinical and radiographic analysis. Eur Spine J. 2009;18(11):1629-1636. doi:10.1007/ s00586-009-1046-1.

135. Hamilton DK, Jones-Quaidoo SM, Sansur C, Shaffrey CI, Oskouian R, Jane JA. Outcomes of bone morphogenetic protein- 2 in mature adults: posterolateral non-instrument-assisted lumbar decompression and fusion. Surg Neurol. 2008;69(5):457-461; discussion 461-462. doi:10.1016/ j.surneu.2007.09.008.

136. Meisel HJ, Schnöring M, Hohaus C, et al. Posterior lumbar interbody fusion using rhBMP-2. Eur Spine J. 2008;17(12):1735-1744. doi:10.1007/ s00586-008-0799-2.

137. Villavicencio AT, Burneikiene S, Nelson EL, Bulsara KR, Favors M, Thramann J. Safety of transforaminal lumbar interbody fusion and intervertebral recombinant human bone morphogenetic protein-2. J Neurosurg Spine. 2005;3(6):436-443. doi:10.3171/ spi.2005.3.6.0436.

138. Kleeman TJ, Ahn UM, Talbot-Kleeman A. Laparoscopic anterior lumbar interbody fusion with rhBMP-2: a prospective study of clinical and radiographic outcomes. Spine (Phila Pa 1976). 2001;26(24):2751-2756.

139. Flouzat-Lachaniette $\mathrm{C}-\mathrm{H}$, Ghazanfari A, Bouthors C, Poignard A, Hernigou P, Allain J. Bone union rate with recombinant human bone morphogenic protein-2 versus autologous iliac bone in PEEK cages for anterior lumbar interbody fusion. Int Orthop. 2014;38(9):2001-2007. doi:10.1007/ s00264-014-2301-6.

140. Malham GM, Giles GG, Milne RL, Blecher 
CM, Brazenor GA. Bone Morphogenetic Proteins in Spinal Surgery: What Is the Fusion Rate and Do They Cause Cancer? Spine (Phila Pa 1976). 2015;40(22):1737-1742. doi:10.1097/ BRS.0000000000001184.

141. Burkus JK, Heim SE, Gornet MF, Zdeblick TA. Is INFUSE bone graft superior to autograft bone? An integrated analysis of clinical trials using the LT-CAGE lumbar tapered fusion device. J Spinal Disord Tech. 2003;16(2):113-122.

142. Baskin DS, Ryan P, Sonntag V, Westmark R, Widmayer MA. A prospective, randomized, controlled cervical fusion study using recombinant human bone morphogenetic protein- 2 with the CORNERSTONE-SR allograft ring and the ATLANTIS anterior cervical plate. Spine (Phila Pa 1976). 2003;28(12):1219-1224; discussion 1225. doi:10.1097/01.BRS.0000065486.22141.CA. 143. Buttermann GR. Prospective nonrandomized comparison of an allograft with bone morphogenic protein versus an iliac-crest autograft in anterior cervical discectomy and fusion. Spine J. 8(3):426-435. doi:10.1016/j.spinee.2006.12.006.

144. Khajavi K, Shen A. Safety and efficacy of bioabsorbable cervical spacers and low-dose rhBMP-2 in multi-level ACDF. Int J spine Surg. 2014;8. doi:10.14444/1009.

145. Tumialán LM, Pan J, Rodts GE, Mummaneni $P$ V. The safety and efficacy of anterior cervical discectomy and fusion with polyetheretherketone spacer and recombinant human bone morphogenetic protein-2: a review of 200 patients. J Neurosurg Spine. 2008;8(6):529-535. doi:10.3171/SPI/2008/8/6/529. 146. Boakye M, Mummaneni P V, Garrett M, Rodts G, Haid R. Anterior cervical discectomy and fusion involving a polyetheretherketone spacer and bone morphogenetic protein. J Neurosurg Spine. 2005;2(5):521-525. doi:10.3171/spi.2005.2.5.0521. 147. Yan L, Chang Z, He B, et al. Efficacy of rhBMP-2 versus iliac crest bone graft for posterior C1-C2 fusion in patients older than 60 years. Orthopedics. 2014;37(1):e51-e57.

148. Sayama C, Hadley C, Monaco GN, et al. The efficacy of routine use of recombinant human bone morphogenetic protein- 2 in occipitocervical and atlantoaxial fusions of the pediatric spine: a minimum of 12 months' follow-up with computed tomography.
J Neurosurg Pediatr. 2015;16(1):14-20. doi:10.3171/ 2015.2.PEDS14533.

149. Hodges SD, Eck JC, Newton D. Retrospective study of posterior cervical fusions with rhBMP-2. Orthopedics. 2012;35(6):e895-e898. doi:10.3928/ 01477447-20120525-30.

150. Hamilton DK, Smith JS, Reames DL, Williams BJ, Chernavvsky DR, Shaffrey CI. Safety, efficacy, and dosing of recombinant human bone morphogenetic protein- 2 for posterior cervical and cervicothoracic instrumented fusion with a minimum 2-year follow-up. Neurosurgery. 2011;69(1):103-111; discussion 111. doi:10.1227/NEU.0b013e318214a9b1. 151. Hamilton DK, Smith JS, Reames DL, Williams BJ, Shaffrey CI. Use of recombinant human bone morphogenetic protein-2 as an adjunct for instrumented posterior arthrodesis in the occipital cervical region: An analysis of safety, efficacy, and dosing. $J$ Craniovertebr Junction Spine. 2010;1(2):107-112. doi:10.4103/0974-8237.77674.

152. Mulconrey DS, Bridwell KH, Flynn J, Cronen GA, Rose PS. Bone morphogenetic protein (RhBMP-2) as a substitute for iliac crest bone graft in multilevel adult spinal deformity surgery: minimum two-year evaluation of fusion. Spine (Phila Pa 1976). 2008;33(20):2153-2159. doi:10.1097/

BRS.0b013e31817bd91e.

153. Luhmann SJ, Bridwell KH, Cheng I, Imamura T, Lenke LG, Schootman M. Use of bone morphogenetic protein-2 for adult spinal deformity. Spine (Phila Pa 1976). 2005;30(17 Suppl):S110-S117. 154. Kim HJ, Buchowski JM, Zebala LP, Dickson DD, Koester L, Bridwell KH. RhBMP-2 is superior to iliac crest bone graft for long fusions to the sacrum in adult spinal deformity: 4- to 14-year follow-up. Spine (Phila Pa 1976). 2013;38(14):1209-1215. doi:10.1097/BRS.0b013e31828b656d. 155. Maeda T, Buchowski JM, Kim YJ, Mishiro T, Bridwell $\mathrm{KH}$. Long adult spinal deformity fusion to the sacrum using rhBMP-2 versus autogenous iliac crest bone graft. Spine (Phila Pa 1976).

2009;34(20):2205-2212. doi:10.1097/

BRS.0b013e3181b0485c.

156. Rahman RK, Buchowski JM, Stephens B, Dorward IG, Koester LA, Bridwell KH. Comparison of TLIF with rhBMP-2 versus no TLIF and higher posterolateral rhBMP-2 dose at L5-S1 for long fusions to 
the sacrum with sacropelvic fixation in patients with primary adult deformity. Spine (Phila Pa 1976).

2013;38(26):2264-2271. doi:10.1097/

BRS.0000000000000045.

157. Abd-El-Barr MM, Cox JB, Antonucci MU, Bennett J, Murad GJA, Pincus DW. Recombinant human bone morphogenetic protein-2 as an adjunct for spine fusion in a pediatric population. Pediatr Neurosurg. 2011;47(4):266-271. doi:10.1159/ 000335424.

158. Lindley TE, Dahdaleh NS, Menezes AH, Abode-Iyamah KO. Complications associated with recombinant human bone morphogenetic protein use in pediatric craniocervical arthrodesis. J Neurosurg Pediatr. 2011;7(5):468-474. doi:10.3171/ 2011.2.PEDS10487.

159. Fahim DK, Whitehead WE, Curry DJ, Dauser RC, Luerssen TG, Jea A. Routine use of recombinant human bone morphogenetic protein- 2 in posterior fusions of the pediatric spine: safety profile and efficacy in the early postoperative period. Neurosurgery. 2010;67(5):1195-1204; discussion 1204. doi:10.1227/ NEU.0b013e3181f258ba.

160. O'Shaughnessy BA, Kuklo TR, Ondra SL. Surgical treatment of vertebral osteomyelitis with recombinant human bone morphogenetic protein-2.

Spine (Phila Pa 1976). 2008;33(5):E132-E139. doi:10.1097/BRS.0b013e3181657ee3.

161. Allen RT, Lee Y-P, Stimson E, Garfin SR. Bone morphogenetic protein-2 (BMP-2) in the treatment of pyogenic vertebral osteomyelitis. Spine (Phila Pa 1976). 2007;32(26):2996-3006. doi:10.1097/

BRS.0b013e31815cde3e.

162. Aryan HE, Lu DC, Acosta FL, Ames CP. Corpectomy followed by the placement of instrumentation with titanium cages and recombinant human bone morphogenetic protein-2 for vertebral osteomyelitis. J Neurosurg Spine. 2007;6(1):23-30. doi:10.3171/spi.2007.6.1.23.

163. Delawi D, Jacobs W, van Susante JLC, et al. OP-1 Compared with Iliac Crest Autograft in Instrumented Posterolateral Fusion: A Randomized, Multicenter Non-Inferiority Trial. J Bone Joint Surg Am. 2016;98(6):441-448. doi:10.2106/JBJS.O.00209. 164. Delawi D, Dhert WJA, Rillardon L, et al. A prospective, randomized, controlled, multicenter study of osteogenic protein-1 in instrumented pos- terolateral fusions: report on safety and feasibility. Spine (Phila Pa 1976). 2010;35(12):1185-1191. doi:10.1097/BRS.0b013e3181d3cf28.

165. Vaccaro AR, Lawrence JP, Patel T, et al. The safety and efficacy of OP-1 (rhBMP-7) as a replacement for iliac crest autograft in posterolateral lumbar arthrodesis: a long-term ( $>4$ years) pivotal study. Spine (Phila Pa 1976). 2008;33(26):2850-2862. doi:10.1097/BRS.0b013e31818a314d. 166. Vaccaro AR, Whang PG, Patel T, et al. The safety and efficacy of OP-1 (rhBMP-7) as a replacement for iliac crest autograft for posterolateral lumbar arthrodesis: minimum 4-year follow-up of a pilot study. Spine J. 8(3):457-465. doi:10.1016/ j.spinee.2007.03.012.

167. Kanayama M, Hashimoto T, Shigenobu K, Yamane S, Bauer TW, Togawa D. A prospective randomized study of posterolateral lumbar fusion using osteogenic protein-1 (OP-1) versus local autograft with ceramic bone substitute: emphasis of surgical exploration and histologic assessment. Spine (Phila Pa 1976). 2006;31(10):1067-1074. doi:10.1097/ 01.brs.0000216444.01888.21.

168. Furlan JC, Perrin RG, Govender P V, et al. Use of osteogenic protein-1 in patients at high risk for spinal pseudarthrosis: a prospective cohort study assessing safety, health-related quality of life, and radiographic fusion. Invited submission from the Joint Section on Disorders of the Spine and P. J Neurosurg Spine. 2007;7(5):486-495. doi:10.3171/SPI-07/09/ 486.

169. Vaccaro AR, Patel T, Fischgrund J, et al. A 2-year follow-up pilot study evaluating the safety and efficacy of op-1 putty (rhbmp-7) as an adjunct to iliac crest autograft in posterolateral lumbar fusions. Eur Spine J. 2005;14(7):623-629. doi:10.1007/ s00586-004-0845-7.

170. Vaccaro AR, Patel T, Fischgrund J, et al. A pilot safety and efficacy study of OP-1 putty (rhBMP-7) as an adjunct to iliac crest autograft in posterolateral lumbar fusions. Eur Spine J. 2003;12(5):495-500. doi:10.1007/s00586-003-0561-8.

171. Vaccaro AR, Patel T, Fischgrund J, et al. A pilot study evaluating the safety and efficacy of OP-1 Putty (rhBMP-7) as a replacement for iliac crest autograft in posterolateral lumbar arthrodesis for degenerative spondylolisthesis. Spine (Phila Pa 1976). 
2004;29(17):1885-1892.

172. Centrella M, McCarthy TL, Canalis E. Platelet-derived growth factor enhances deoxyribonucleic acid and collagen synthesis in osteoblastenriched cultures from fetal rat parietal bone. $E n$ docrinology. 1989;125(1):13-19. doi:10.1210/endo-125-1-13.

173. Sys J, Weyler J, Van Der Zijden T, Parizel P, Michielsen J. Platelet-rich plasma in monosegmental posterior lumbar interbody fusion. Eur Spine J. 2011;20(10):1650-1657. doi:10.1007/ s00586-011-1897-0.

174. Acebal-Cortina G, Suárez-Suárez MA, GarcíaMenéndez C, Moro-Barrero L, Iglesias-Colao R, Torres-Pérez A. Evaluation of autologous platelet concentrate for intertransverse lumbar fusion. Eur Spine J. 2011;20 Suppl 3:361-366. doi:10.1007/ s00586-011-1904-5.

175. Jenis LG, Banco RJ, Kwon B. A prospective study of Autologous Growth Factors (AGF) in lumbar interbody fusion. Spine J. 6(1):14-20.

doi:10.1016/j.spinee.2005.08.014.

176. Hee HT, Majd ME, Holt RT, Myers L. Do autologous growth factors enhance transforaminal lumbar interbody fusion? Eur Spine J.

2003;12(4):400-407. doi:10.1007/ s00586-003-0548-5.

177. Carreon LY, Glassman SD, Anekstein Y, Puno RM. Platelet gel (AGF) fails to increase fusion rates in instrumented posterolateral fusions. Spine (Phila Pa 1976). 2005;30(9):E243-E246; discussion E247. 178. Landi A, Tarantino R, Marotta N, et al. The use of platelet gel in postero-lateral fusion: preliminary results in a series of 14 cases. Eur Spine J.

2011;20 Suppl 1:S61-S67. doi:10.1007/ s00586-011-1760-3.

179. Weiner BK, Walker M. Efficacy of autologous growth factors in lumbar intertransverse fusions. Spine (Phila Pa 1976). 2003;28(17):1968-1970; discussion 1971. doi:10.1097/ 01.BRS.0000083141.02027.48.

180. Lowery GL, Kulkarni S, Pennisi AE. Use of autologous growth factors in lumbar spinal fusion.

Bone. 1999;25(2 Suppl):47S - 50S.

181. Feiz-Erfan I, Harrigan M, Sonntag VKH, Harrington TR. Effect of autologous platelet gel on early and late graft fusion in anterior cervical spine surgery. J Neurosurg Spine. 2007;7(5):496-502. doi:10.3171/SPI-07/11/496.

182. Tohmeh AG, Watson B, Tohmeh M, Zielinski XJ. Allograft cellular bone matrix in extreme lateral interbody fusion: preliminary radiographic and clinical outcomes. ScientificWorldJournal. 2012;2012:263637. doi:10.1100/2012/263637.

183. Ammerman JM, Libricz J, Ammerman MD. The role of Osteocel Plus as a fusion substrate in minimally invasive instrumented transforaminal lumbar interbody fusion. Clin Neurol Neurosurg.

2013;115(7):991-994. doi:10.1016/

j.clineuro.2012.10.013.

184. Kerr EJ, Jawahar A, Wooten T, Kay S, Cavanaugh DA, Nunley PD. The use of osteoconductive stem-cells allograft in lumbar interbody fusion procedures: an alternative to recombinant human bone morphogenetic protein. J Surg Orthop Adv. 2011;20(3):193-197.

185. Gan Y, Dai K, Zhang P, Tang T, Zhu Z, Lu J. The clinical use of enriched bone marrow stem cells combined with porous beta-tricalcium phosphate in posterior spinal fusion. Biomaterials. 2008;29(29):3973-3982. doi:10.1016/ j.biomaterials.2008.06.026.

186. Eastlack RK, Garfin SR, Brown CR, Meyer SC. Osteocel plus cellular allograft in anterior cervical discectomy and fusion: evaluation of clinical and radiographic outcomes from a prospective multicenter study. Spine (Phila Pa 1976).

2014;39(22):E1331-E1337. doi:10.1097/

BRS.0000000000000557.

187. McAnany SJ, Ahn J, Elboghdady IM, et al. Mesenchymal stem cell allograft as a fusion adjunct in one- and two-level anterior cervical discectomy and fusion: a matched cohort analysis. Spine J. 2016;16(2):163-167. doi:10.1016/

j.spinee.2015.02.037.

188. Vanichkachorn J, Peppers T, Bullard D, Stanley SK, Linovitz RJ, Ryaby JT. A prospective clinical and radiographic 12-month outcome study of patients undergoing single-level anterior cervical discectomy and fusion for symptomatic cervical degenerative disc disease utilizing a novel viable allogeneic, cancellous, bone matrix (tri. Eur Spine J. February 2016. doi:10.1007/s00586-016-4414-7.

189. Cunningham BW, Atkinson BL, Hu N, et al. 
Ceramic granules enhanced with B2A peptide for lumbar interbody spine fusion: an experimental study using an instrumented model in sheep. J Neurosurg Spine. 2009;10(4):300-307. doi:10.3171/ 2009.1.SPINE08565.

190. Qian JJ, Bhatnagar RS. Enhanced cell attachment to anorganic bone mineral in the presence of a synthetic peptide related to collagen. J Biomed Mater Res. 1996;31(4):545-554. doi:10.1002/(SICI)1097-4636(199608)31:4\&lt;545::AIDJBM15\&gt;3.0.CO;2-F.

191. Lauweryns $P$, Raskin Y. Prospective analysis of a new bone graft in lumbar interbody fusion: results of a 2- year prospective clinical and radiological study. Int J Spine Surg. 2015;9. doi:10.14444/2002. 192. Arnold PM, Sasso RC, Janssen ME, et al. Efficacy of i-Factor ${ }^{\mathrm{TM}}$ Bone Graft versus Autograft in Anterior Cervical Discectomy and Fusion: Results of the Prospective Randomized Single-blinded Food and Drug Administration Investigational Device Exemption Study. Spine (Phila Pa 1976). January 2016. doi:10.1097/BRS.0000000000001466.

193. Bhatnagar RS, Qian JJ, Wedrychowska A, Smith N. Construction of Biomimetic Environments with A Synthetic Peptide Analogue of Collagen. In: Vol 530. Cambridge Univ Press; 1998:43.

194. Sardar Z, Alexander D, Oxner W, et al. Twelve-month results of a multicenter, blinded, pilot study of a novel peptide (B2A) in promoting lumbar spine fusion. J Neurosurg Spine. 2015;22(4):358-366. doi:10.3171/2013.11.SPINE121106.

195. Smucker JD, Bobst JA, Petersen EB, Nepola J V., Fredericks DC. B2A peptide on ceramic granules enhance posterolateral spinal fusion in rabbits compared with autograft. Spine (Phila Pa 1976).

2008;33(12):1324-1329. doi:10.1097/

BRS.0b013e3181732a74.

196. Mobbs RJ, Maharaj M, Rao PJ. Clinical outcomes and fusion rates following anterior lumbar interbody fusion with bone graft substitute i-FACTOR, an anorganic bone matrix/P-15 composite. J Neurosurg Spine. 2014;21(6):867-876. doi:10.3171/ 2014.9.SPINE131151.

\section{Disclosures \& COI}

James J. Benedict has a financial interest in Cerapedics, Inc. in the form of common stock. Michael
Fehlings reports no disclosures or conflicts of interest. Mike Janssen reports research support from the Spine Education \& Research Foundation and stock and honoraria from Cerapedics. Abhijeet Kadam reports no disclosures or conflicts of interest. Christopher Kepler reports no disclosures or conflicts of interest. Millhouse reports stock ownership in Globus Medical, outside the submitted work. Kris Radcliff reportsstock ownership and acting as scientific advisor to 4Web Medical; board membership in ACSR; travel expenses and other financial or material support from Altus Spine; paid consultancy and research support from DePuy, IP royalties, paid consultancy, research support from Globus Medical; unpaid consultancy for LDR; paid consultancy and research support from Medtronic, other financial or material support from NEXXT Spine and Nuvasive; paid consultancy other financial or material support, and travel expeses from Orthofix; IP royalties and paid consultancy from Orthopedic Sciences; research support from Pacira Pharmaceuticals, research support from Paradigm Spine; and other financial or material support from Stryker. Rick Sasso reports royalties and personal fees from Medtronic, outside the submitted work. Vaccaro reports other from Replication Medica, personal fees from DePuy, personal fees from Medtronics, personal fees from Stryker Spine, personal fees and other from Globus, other from Paradigm Spine, personal fees and other from Stout Medical, other from Progressive Spinal Technologies, other from Advanced Spinal Intellectual Properties, personal fees from Aesculap, other from Spine Medica, other from Computational Biodynamics, other from Spinology, other from In Vivo, other from Flagship Surgical, other from Cytonics, other from Bonovo Orthopaedics, other from Electrocore, other from Gamma Spine, other from Location Based Intelligence, other from FlowPharma, other from R.S.I., personal fees from Gerson Lehrman Group, from Guidepoint Global, personal fees from Medacorp, other from Rothman Institute and Related Properties, other from AO Spine, personal fees and other from Innovative Surgical Design, other from Association of Collaborative Spine Research, personal fees from Orthobullets, personal fees from Thieme, personal fees from Jaypee, personal fees from Elsevier, personal fees from Taylor Francis/Hodder and Stoughton, personal fees from

Downloaded from http://ijssurgery.com/ by guest on April 26, 2023 
Expert Testimony, personal fees from Ellipse, personal fees from Vertex, personal fees from Avaz Surgical, other from Clinical Spine Surgery, outside the submitted work.

\section{Corresponding Author}

Abhijeet Kadam, MD, Pennsylvania Hospital of the University of Pennsylvania Health System, Philadel- phia, PA 19107. abhijeetsr71@gmail.com.

Published 22 September 2016.

This manuscript is generously published free of charge by ISASS, the International Society for the Advancement of Spine Surgery. Copyright @ 2016 ISASS. To see more or order reprints or permissions, see http://ijssurgery.com. 